\title{
Phonology
}

http://journals.cambridge.org/PHO

Additional services for Phonology:

Email alerts: $\underline{\text { Click here }}$

Subscriptions: Click here

Commercial reprints: $\underline{\text { Click here }}$

Terms of use : $\underline{\text { Click here }}$

\section{Phonetic variability and grammatical knowledge: an articulatory study of Korean place assimilation}

Alexei Kochetov and Marianne Pouplier

Phonology / Volume 25 / Issue 03 / December 2008, pp 399 - 431

DOI: 10.1017/S0952675708001553, Published online: 24 February 2009

Link to this article: http://journals.cambridge.org/abstract S0952675708001553

How to cite this article:

Alexei Kochetov and Marianne Pouplier (2008). Phonetic variability and grammatical knowledge: an articulatory study of Korean place assimilation.

Phonology, 25, pp 399-431 doi:10.1017/S0952675708001553

Request Permissions : $\underline{\text { Click here }}$ 


\title{
Phonetic variability and grammatical knowledge : an articulatory study of Korean place assimilation*
}

\author{
Alexei Kochetov \\ University of Toronto \\ Marianne Pouplier \\ Ludwig Maximilians University, Munich
}

\begin{abstract}
The study reported here uses articulatory data to investigate Korean place assimilation of coronal stops followed by labial or velar stops, both within words and across words. The results show that this place-assimilation process is highly variable, both within and across speakers, and is also sensitive to factors such as the place of articulation of the following consonant, the presence of a word boundary and, to some extent, speech rate. Gestures affected by the process are generally reduced categorically (deleted), while sporadic gradient reduction of gestures is also observed. We further compare the results for coronals to our previous findings on the assimilation of labials, discussing implications of the results for grammatical models of phonological/phonetic competence. The results suggest that speakers' language-particular knowledge of place assimilation has to be relatively detailed and context-sensitive, and has to encode systematic regularities about its obligatory/variable application as well as categorical/gradient realisation.
\end{abstract}

\section{Introduction}

Traditionally, phonological theory has been concerned almost exclusively with invariant, categorical aspects of phonological entities or processes. These aspects of speech have been assumed to crucially reflect speakers' implicit phonological knowledge, i.e. their linguistic competence

* We gratefully acknowledge Minjung Son's contribution to this study. We also thank John Alderete, Stuart Davis, Louis Goldstein, Yoonjung Kang, three anonymous reviewers and an associate editor of Phonology, as well as the audience of the International Conference on East Asian Linguistics at the University of Toronto for helpful comments and suggestions. This work was supported by NIH grant 00493 to Haskins Laboratories, a Social Sciences and Humanities Research Council of Canada grant to Alexei Kochetov, and an Emmy-Noether grant of the Deutsche Forschungsgemeinschaft to Marianne Pouplier. All errors are our own. 


\section{Alexei Kochetov and Marianne Pouplier}

(Chomsky \& Halle 1968). Variability and gradience, on the other hand, have been widely viewed as external to the grammar proper, reflecting speakers' performance. Investigations of these aspects of phonological processes have therefore been relegated to the disciplines of sociolinguistics and phonetics. Much recent work in phonology, however, has questioned these traditional assumptions, showing that at least some types of variability (optionality) and gradience (partial phonetic realisation) are part of linguistic competence (see e.g. Anttila 2003, 2007). One of the most important findings of this research is that differences between obligatory and optional or between categorical and gradient aspects of phonological structure are rarely clear-cut, with both types governed by apparently the same general factors. In particular, many variable and gradient speech phenomena exhibit regularities akin to obligatory and categorical phonological properties. For example, the well-known process of word-final $t / d$-deletion in English (e.g. lost $\sim$ los, west side $\sim$ wes side) is highly variable, yet sensitive to a grammatical variable - the sonority of the following segment (Guy 1991, Coetzee 2004). Phonetic differences between the 'clear' and 'dark' allophones of English /1/ in many contexts (e.g. free-ly vs. feel-y) are gradient, yet clearly influenced by grammatical factors syllable position, morphological structure and prosodic boundary strength (Giles \& Moll 1975, Sproat \& Fujimura 1993, Boersma \& Hayes 2001, Scobbie et al. 2007). Another interesting finding is that speakers possess internalised knowledge of many variable/gradient regularities found in speech processes, in the same way as they possess knowledge of obligatory/ categorical regularities. For example, speakers of Hungarian who apply the process of vowel harmony to novel stems in a 'wug' test do it in a way that closely matches the variation and relative frequencies observed in the lexicon (Hayes \& Londe 2006). Native English listeners are sensitive to the degree of contextual reduction of gestures (e.g. the tongue-tip gestures of $/ \mathrm{t} /$ and $/ \mathrm{d} /$ in late calls, road collapsed), and actively use this knowledge in word-recognition and lexical decision tasks (Wright \& Kerswill 1989, Nolan 1992, Marslen-Wilson \& Warren 1994; but see Gow 2003).

In this paper we examine some less studied variable aspects of one relatively well-known phonological process-place assimilation in Korean. We focus on the assimilation (or its absence) of coronal stops to following labial and velar stops, both within and across words. Tracking articulation by means of an articulograph (EMMA; Perkell et al. 1992), we examine the presence or absence of assimilation in the speech of three native speakers of Korean. We show that this place-assimilation process is indeed highly variable, both within and across speakers, and that it is also sensitive to such factors as the place of articulation of the following consonant, the presence of a word boundary and, to some extent, speech rate. Articulatory gestures affected by the process are generally reduced categorically (deleted), while sporadic gradient reduction of gestures is also observed. We further compare the results for coronals to our previous findings on the assimilation of labials, discussing implications of the results for grammatical models of phonological/phonetic competence. 
An experimental investigation of Korean assimilation is of particular interest in the context of recent studies that examine the phonetic details of place-assimilation processes in various languages. These studies have revealed that place-assimilation processes may be implemented rather differently within a given language - categorically or gradiently, obligatorily or optionally - depending on a number of factors, both within and across speakers' productions. For example, Farnetani \& Busà (1994), who examined Italian nasal place assimilation using electropalatography (EPG), found that the implementation of the process is highly contextspecific. Their speakers assimilated word-final $/ \mathrm{n} /$ categorically before velar $/ \mathrm{k} /$ and gradiently before postalveolar $/ \mathrm{f} /$. In the former case, the lingual contact during the nasal was in the velar area, rather than in the alveolar area; in the latter case, the contact was intermediate between the alveolar and postalveolar areas, indicative of gestural 'blending' (Browman \& Goldstein 1989). Before the alveolar trill $/ \mathrm{r} /$, the lingual gesture of $/ \mathrm{n} /$ was usually absent altogether, i.e. categorically reduced (deleted). These articulatory strategies were consistent across the three speakers examined in the study. Interestingly, the speakers differed in how they realised $/ \mathrm{n} /$ in yet another context, before the postalveolar fricative $/ \mathrm{s} /$. Two of the speakers produced nasals with different degrees of alveolar/postalveolar blending; the other speaker produced a nasal fully assimilated in place, yet gradiently reduced in duration (with nasality realised mainly on the preceding vowel). Similar context-specific effects in the implementation of nasal place assimilation have been observed for Catalan (Recasens \& Pallarès 2001) and Castilian Spanish (Honorof 1999). Earlier instrumental studies of English coronal place assimilation have established that the process can be gradient and variable, presumably characteristic of casual style and fast speech rate (Hardcastle \& Roach 1979, Barry 1991, Nolan 1992, Byrd 1996). Some recent findings, however, suggest that the implementation of the process is more complex. Ellis \& Hardcastle (2002), who examined the production of British English nasal + velar sequences using both EPG and EMMA, found considerable inter- and intra-speaker differences. Four of their eight subjects showed categorical place assimilation in all their productions - a complete reduction of the alveolar gesture accompanied by an extension of the dorsal gesture. Two other subjects varied between no assimilation (a fully realised alveolar gesture) and categorical assimilation. The other two subjects showed gradient assimilation-a continuum of coronal gesture realisations from complete closure through a partially reduced gesture to a completely reduced gesture. Taken together, these studies suggest that place-assimilation processes are more complex than has been previously assumed. They also suggest that speakers' language-particular competence, their implicit phonological/phonetic 'knowledge' of place assimilation, has to be relatively detailed and context-sensitive, and has to encode systematic regularities in its obligatory/variable application and categorical/gradient realisation. The goal of this paper is to explore systematic regularities in the application and realisation of Korean place 
assimilation, thus contributing to a better understanding of language- and speaker-particular phonological/phonetic competence in general.

The paper is organised as follows: in $\$ 2$ we describe key properties of Korean place assimilation, review some theoretical accounts of the process and set up predictions for an experimental study. $\S 33$ and 4 present experimental results on coronal and labial stops respectively. In $\$ 5$, we discuss implications of our results for accounts of Korean place assimilation, as well as for modelling variability and gradience in general.

\section{Korean place assimilation: background and predictions}

\subsection{Key properties}

The place-assimilation process of Korean is interesting in a number of ways. First, the process is inherently variable, in that it is optional. According to Kim-Renaud (1991: 231), it occurs in colloquial, casual speech styles rather than in formal, careful styles. Jun (1995) describes place assimilation as characteristic of fast, rather than slow speech. Speakers appear to be aware of the phenomenon, as prescriptive grammars explicitly discourage the use of assimilated variants (Kim-Renaud 1991: 250).

Second, the process has been described (Kim-Renaud 1991: 231-234, Ahn 1998) as exhibiting certain place of articulation asymmetries in the consonants which are affected (targets) and in those which induce the assimilatory change (triggers). Thus coronal stops optionally assimilate in place to following labials and dorsals (1a). Note that underlying $/ \mathrm{t}^{\mathrm{h}} /$ and $/ \mathrm{s} /$ in coda position are realised as lenis unreleased [ $\left.\mathrm{t}^{\prime}\right]$, as a result of laryngeal and manner neutralisation processes. Labial stops optionally assimilate to following dorsals (1b). They do not, however, assimilate to following coronals (1c). Finally, dorsals assimilate neither to labials nor to coronals (1d). Underlying lenis stops become fortis when preceded by stops and are voiced between sonorants, as a result of post-obstruent tensing and intersonorant voicing processes (Kim-Renaud 1991: 231-234, Ahn 1998).

\begin{tabular}{|c|c|c|c|}
\hline & $\begin{array}{l}\text { unassimilated } \\
\text { (careful style) }\end{array}$ & $\begin{array}{l}\text { assimilated } \\
\text { (casual style) }\end{array}$ & \\
\hline $\begin{array}{l}\text { /pat }{ }^{\mathrm{h}}-\text { pota/ } \\
\text { /pat }-\mathrm{kwa} / \\
\text { /os-pocaki/ } \\
\text { /os-kolim/ }\end{array}$ & $\begin{array}{l}\text { [pat'p'oda] } \\
\text { [pat'k'wa] } \\
\text { [ot'p'odzagi] } \\
\text { [ot'k'orim] }\end{array}$ & $\begin{array}{l}\text { [pap'p'oda] } \\
\text { [pak'k’wa] } \\
\text { [op'p'odzagi] } \\
\text { [ok'k'or'tim] }\end{array}$ & $\begin{array}{l}\text { 'rather than the field' } \\
\text { 'field and' } \\
\text { 'clothes wrapper' } \\
\text { 'clothes wrapper' }\end{array}$ \\
\hline $\begin{array}{l}\text { /pap-kitlis/ } \\
\mid \mathrm{t}^{\mathrm{h}} \mathrm{op}-\mathrm{k}^{\mathrm{h}} \mathrm{al} /\end{array}$ & $\begin{array}{l}\text { [pap'k'tirit' } \\
{\left[\mathrm{t}^{\mathrm{h}} \mathrm{op}^{7} \mathrm{k}^{\mathrm{h}} \mathrm{hl}\right]}\end{array}$ & 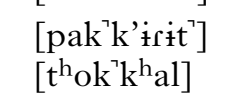 & $\begin{array}{l}\text { 'rice bowl' } \\
\text { 'handsaw' }\end{array}$ \\
\hline $\begin{array}{l}\mid \text { pap-to/ } \\
\mid \text { kap-ca| }\end{array}$ & $\begin{array}{l}\text { [pap't'o] } \\
{\left[\text { kap }^{\top} t^{\prime} a\right]}\end{array}$ & $\begin{array}{l}*[\text { patt'o }] \\
*\left[\text { kat }^{\top} \text { t'a }^{\prime} \mathrm{a}\right]\end{array}$ & $\begin{array}{l}\text { 'rice also' } \\
\text { 'let's pay back' }\end{array}$ \\
\hline $\begin{array}{l}\mid \text { kuk-po/ } \\
\mid \text { pak-to/ }\end{array}$ & $\begin{array}{l}\text { [kuk'p'o] } \\
\text { [pak't'o] }\end{array}$ & $\begin{array}{l}*[\text { kup'p'o] } \\
*[\text { patt'o] }\end{array}$ & $\begin{array}{l}\text { 'national treasury' } \\
\text { 'outside also' }\end{array}$ \\
\hline
\end{tabular}


In sum, the data show that Korean velars are not susceptible to assimilation, while labials and coronals are. In addition, velars and labials can trigger assimilation of preceding consonants, while coronals systematically fail to do so. This property of Korean place assimilation has received considerable attention in recent phonological literature, and is often interpreted as evidence for the relative markedness of places of articulation: dorsal > labial > coronal (Jun 1995, de Lacy 2002; but see Rice 1999, Hume 2003).

The third, and least understood, property of Korean place assimilation is its possibly gradient (partial) phonetic realisation. Jun (1996), who conducted an intraoral air-pressure experiment with 14 speakers producing utterances containing a $/ \mathrm{pk} /$ sequence, inferred indirectly from the airpressure patterns that the lip gesture of $/ \mathrm{p} /$ was often reduced gradiently in terms of a partial reduction in movement amplitude, rather than being absent categorically $(/ \mathrm{p}+\mathrm{k} / \rightarrow[\mathrm{p} \mathrm{k}]$; subscript segments here and below indicate segments whose gestures are gradiently reduced). He proposed that Korean labial place assimilation is a gradient phonetic process, akin to English coronal assimilation (e.g. tha $\left[_{\mathrm{t}}\right]$ boy, tha $\left[_{\mathrm{t}}\right]$ girl) (Nolan 1992, Browman \& Goldstein 1995). By extension, Korean coronal place assimilation has also been assumed to be gradient (Jun 1995: 171), although this process has not been instrumentally investigated.

Another study on Korean labial assimilation, however, revealed different results (Son et al. 2007). This study used articulography (EMMA), in which lip movement is directly tracked by sensors attached to the upper and lower lips. The three speakers employed in the study clearly exhibited categorical assimilation: the lip gesture of $/ \mathrm{p} /$ was either fully realised ([pk]) or absent altogether ([kk]). Consistently with Jun's findings, however, the speakers showed considerable within- and cross-speaker variation in the rate of assimilation/gestural reduction. That is, while the assimilation process exhibited little phonetic variability in terms of the degree to which the lip closure was realised, it was variable in that it was probabilistic in its occurrence. None of the three speakers, however, reduced $/ \mathrm{p} /$ across words, contrary to the observations of Jun (1995). Whether this difference can be attributed to differences in stimulus composition between the two studies or was conditioned by the different measurement techniques employed is unclear. The results nonetheless suggest that at least some speakers' implementation of the process is sensitive to prosodic/word boundaries. We will return to these results in $\S 4$.

Of the various properties of Korean place assimilation, variability (optionality) and gradience (partial phonetic realisation) will be our main focus, although place target/trigger asymmetries and (in)sensitivity to boundaries will also be of interest.

\subsection{Previous formal accounts}

Most phonological accounts of Korean place assimilation have been concerned with capturing the place target/trigger asymmetries, rather than 


\section{Alexei Kochetov and Marianne Pouplier}

variability and gradience. Kim-Renaud (1991: 236-237), for example, uses $S P E$-style formalism for her rule of 'anterior assimilation' (2), with [anterior] assumed to include both coronals and labials. The optionality of the rule is marked diacritically; optional rules are assumed to apply late in the derivation (cf. postlexical rules in Lexical Phonology; Kiparsky 1985).

(2) Anterior assimilation (optional)

$[-$ cont,+ ant $] \rightarrow[\alpha$ Place $] / \ldots[-$ cor, $\alpha$ Place $]$

Ahn (1998: 106f) proposes a feature-geometry account of the process, in which regressive assimilation is triggered by underspecification of consonants for place. He adopts representations in which coronals are underspecified for place (a bare [Place] node), labials are partially underspecified ([Place [peripheral]]) and velars are fully specified ([Place [peripheral [dorsal]]]). Fully and partially underspecified segments - coronals and labials-acquire place features from following more structurally complex consonants (3a). Assimilation of labials and velars to following coronals, and of velars to labials and coronals, is ruled out, as there are no features to spread ((3b); cf. the feature-geometry account in Cho 1990).
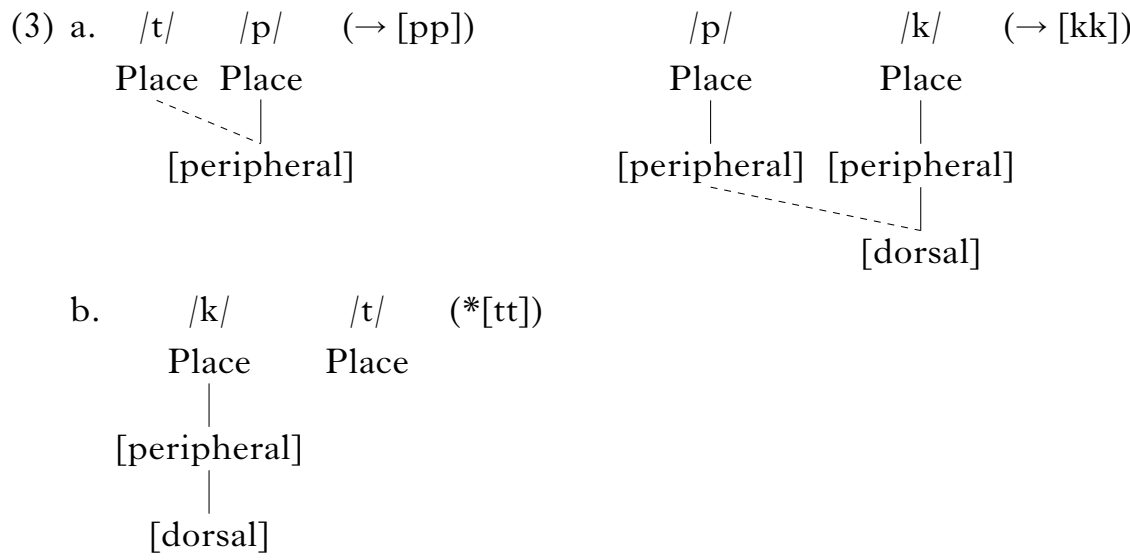

Ahn briefly notes that the process applies variably (1998: 100); however, what it is that conditions this variability is not part of the account. Notice also that the feature-spreading account does not allow for the gradient, partially phonetic implementation of assimilation (Browman \& Goldstein 1989, Jun 1995): segments that acquire place features through spreading (e.g. $/ \mathrm{t} /$ in $/ \mathrm{tp} /, / \mathrm{p} /$ in $/ \mathrm{pk} /$ ) would no longer receive [coronal] or [labial] features at the end of derivation, and thus would be unambiguously interpreted phonetically as $[\mathrm{p}]$ or $[\mathrm{k}]$.

Jun $(1995,2004)$ proposes an optimality-theoretic account of Korean place assimilation in the context of a cross-linguistic typology of place assimilation. His analysis of Korean attempts to capture not only place target/trigger asymmetries, but also its optional and (apparently) gradient 
implementation. Jun adopts gestural representations, where the place features [labial], [coronal] and [dorsal] are represented as the articulatory gestures Lips, Tongue Tip and Tongue Body respectively (Browman \& Goldstein 1989, 1992). The gestural display in (4) schematically represents assimilation of coronal $/ \mathrm{t} /$ to velar $/ \mathrm{k} /$ (based on Jun 2004: 72). The unassimilated sequence has two partly overlapped oral gesture constrictions, Tongue Tip and Tongue Body, shown as shaded boxes. The length of the boxes represents the time interval during which the vocal tract is actively controlled by a given gesture. The assimilated sequence $[\mathrm{kk}]$ has only one gesture, Tongue Body, extended in time compared to a singleton $/ \mathrm{k} /$; the Tongue Tip gesture has been fully reduced (deleted). Thus, in terms of articulation, categorical place assimilation involves the (complete) reduction of one gesture and the extension of the other gesture.

(4)

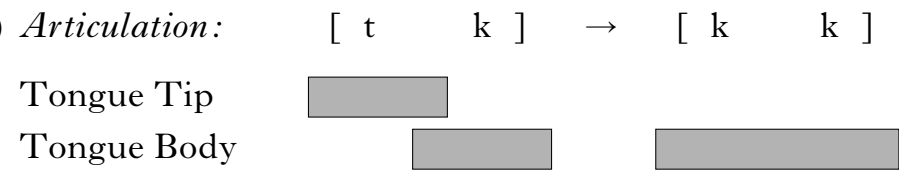

According to Jun, reduction of gestures (and ultimately assimilation) is triggered by pressure to 'conserve articulatory effort' on the part of the speaker (Lindblom 1990, Kirchner 1998). He formalises this factor as an optimality-theoretic markedness constraint Weakening (5a). In the vein of $\mathrm{H} \& \mathrm{H}$ (hypo- and hyper-articulation) theory (Lindblom 1990), this markedness constraint is in conflict with a set of perceptually motivated faithfulness constraints, which require the speaker to make more effort to 'preserve' sounds that are more perceptually salient and relax their articulation of sounds that are less perceptually salient. The Preserve(place) constraints relevant to the analysis of Korean are shown in (5b) (based on Jun 2004: 70ff).

(5) a. Weakening

Conserve articulatory effort.

b. Pres(pl[dors])

Preserve acoustic cues to [dorsal].

$\operatorname{Pres}(\mathrm{pl}[\mathrm{lab}])$

Preserve acoustic cues to [labial].

$\operatorname{PrEs}(\mathrm{pl}[\mathrm{cor}])$

Preserve acoustic cues to [coronal].

$\operatorname{Pres}(\mathrm{pl}[$ _ cor $]$ )

Preserve acoustic place cues before [coronal].

Ranking the Weakening constraint above the Preserve constraints for [labial] and [coronal] results in the reduction of corresponding gestures (cf. (6a)). Ranking Pres(pl[__ cor]) above the Weakening constraint ensures that gestures are not reduced before coronals. The equivalent ranking of PRES(pl[dors]) prevents the reduction of velar gestures (see Jun 


\section{Alexei Kochetov and Marianne Pouplier}

2004: $76 \mathrm{f}$ for details). ${ }^{1}$ This ranking is capable of generating the pattern of Korean place assimilation as it has been described for the fast/informal register. Other PrEserve constraints, omitted here, ensure the regressive directionality of the process and the lack of deletion as a repair strategy; see Jun (2004) for details. Note that the analysis does not refer to prosodic (word) boundaries, therefore assimilation is expected to apply both within and across words. Under this ranking, an input sequence /tk/ (within words or across words) will be always realised as the assimilated [kk], with the Tongue Tip gesture of $/ \mathrm{t} /$ fully reduced, as illustrated in the diagram in (4). An input sequence $/ \mathrm{kt} /$, however, will not be affected.

Optionality of place assimilation is modelled by register-specific re-ranking of the WEAKENING constraint. In the fast/informal register, WEAKENING is ranked above the faithfulness constraints for labial and coronal gestures, resulting in place assimilation (6b); in the slow/formal register, these constraints are re-ranked, resulting in unassimilated outputs. The ranking of the Weakening and Preserve constraints in the grammar is therefore variable (as opposed to strict): both kinds of rankings are probabilistically possible, although tied to respective registers. In this sense, Jun's $(1995,2004)$ approach predates the later development of Stochastic OT (Boersma 1998, Boersma \& Hayes 2001).

(6) a. Register: fast/informal

$$
\begin{aligned}
& \operatorname{Pres}(\mathrm{pl}[\text { dors }]), \operatorname{Pres}\left(\mathrm { pl } \left[{ }_{\text {_ cor }]) \gg} \gg\right.\right. \\
& \text { Weakening } \gg \\
& \operatorname{Pres}(\mathrm{pl}[\mathrm{lab}]), \operatorname{Pres}(\mathrm{pl}[\mathrm{cor}])
\end{aligned}
$$

Output: [kp, kt, pt, kk (*pk), kk (*tk), pp (*tp)], etc.
b. Register: slow/formal
$\operatorname{Pres}(\mathrm{pl}[$ dors $]), \operatorname{Pres}(\mathrm{pl}[\ldots$ cor $])$, $\operatorname{Pres}(\mathrm{pl}[\mathrm{lab}]), \operatorname{Pres}(\mathrm{pl}[\mathrm{cor}]) \gg$
WEAKENING

Output: [kp, kt, pt, pk, tk, tp], etc.

Finally, Jun models gradience in place assimilation by introducing gradient Weakening and Preserve constraints and refining the set of register-specific rankings (cf. Kirchner 1998). Sample rankings of such constraints are shown in Table I, where the WeAkening constraints $\mathrm{W}_{0.1 \mathrm{x}}-\mathrm{W}_{1 \mathrm{x}}$ prohibit producing gestures whose effort cost is above a given amount (in decreasing order), the Preserve constraints $\mathrm{P}_{10}-\mathrm{P}_{100}$ require

1 Jun (2004: 76f) motivates the rankings of the PrEserve(place) constraints on the basis of acoustic/perceptual considerations. Thus, the higher ranking of Pres(pl[dors]) relative to Pres(pl[lab]) and Pres(pl[cor]) is based on the observation that unreleased velars are more acoustically salient than other places, being characterised by the convergence of F2 and F3 transitions. The lower ranking of Pres(pl[cor]) relative to PREs(pl[lab]) and PREs(pl[dors]) is attributed to the overall poor acoustic cues to unreleased coronals compared to unreleased labials and velars. Finally, the higher ranking of $\operatorname{PRES}(\mathrm{pl}[$ _ cor]) relative to $\operatorname{PRES}(\mathrm{pl}[\mathrm{lab}])$ is presumably due to the greater acoustic salience of $\mathrm{C} 1$ place before coronals than before noncoronals, since $\mathrm{C} 1$ gestures are not masked by coronal gestures of $\mathrm{C} 2$, which tend to be implemented relatively rapidly. See Kochetov \& So (2007) for a perceptual investigation of these claims. 


\begin{tabular}{|c|c|c|c|c|c|}
\hline \multirow[t]{2}{*}{ register } & \multicolumn{2}{|c|}{ slow/formal } & $\Leftrightarrow$ & \multicolumn{2}{|c|}{ fast/informal } \\
\hline & A & B & $\ldots$ & $\mathrm{J}$ & $\mathrm{K}$ \\
\hline \multirow{14}{*}{ ranking } & $\mathrm{P}_{10}$ & $\mathrm{P}_{10}$ & $\ldots$ & $\mathrm{W}_{1 \mathrm{x}}$ & $\mathrm{W}_{1 \mathrm{x}}$ \\
\hline & $\mathrm{P}_{20}$ & $\mathrm{P}_{20}$ & $\ldots$ & $\mathrm{W}_{0 \cdot 9 \mathrm{x}}$ & $\mathrm{W}_{0 \cdot 9 \mathrm{x}}$ \\
\hline & $\ldots$ & $\ldots$ & $\ldots$ & $\mathrm{W}_{0 \cdot 8 \mathrm{x}}$ & $\mathrm{W}_{0 \cdot 8 \mathrm{x}}$ \\
\hline & $\mathrm{P}_{70}$ & $\mathrm{P}_{70}$ & $\cdots$ & $\mathrm{W}_{0 \cdot 7 \mathrm{x}}$ & $\mathrm{W}_{0 \cdot 7 \mathrm{x}}$ \\
\hline & $\mathrm{P}_{80}$ & $\mathrm{P}_{80}$ & $\ldots$ & $\ldots$ & \\
\hline & $\mathrm{P}_{90}$ & $\mathrm{P}_{90}$ & $\cdots$ & $\mathrm{W}_{0 \cdot 2 \mathrm{x}}$ & $\mathrm{W}_{0 \cdot 2 \mathrm{x}}$ \\
\hline & $\mathrm{P}_{100}$ & $\mathrm{~W}_{1 \mathrm{x}}$ & $\ldots$ & $\mathrm{P}_{10}$ & $\mathrm{~W}_{0 \cdot 1 \mathrm{x}}$ \\
\hline & $\mathrm{W}_{1 \mathrm{x}}$ & $\mathrm{P}_{100}$ & $\ldots$ & $\mathrm{W}_{0 \cdot 1 \mathrm{x}}$ & $\mathrm{P}_{10}$ \\
\hline & $\mathrm{W}_{0 \cdot 9 \mathrm{x}}$ & $\mathrm{W}_{0 \cdot 9 \mathrm{x}}$ & $\ldots$ & $\mathrm{P}_{20}$ & $\mathrm{P}_{20}$ \\
\hline & $\mathrm{W}_{0 \cdot 8 \mathrm{x}}$ & $\mathrm{W}_{0 \cdot 8 \mathrm{x}}$ & $\ldots$ & $\ldots$ & $\ldots$ \\
\hline & $\mathrm{W}_{0 \cdot 7 \mathrm{x}}$ & $\mathrm{W}_{0 \cdot 7 \mathrm{x}}$ & . & $\mathrm{P}_{70}$ & $\mathrm{P}_{70}$ \\
\hline & . & & $\cdots$ & $\mathrm{P}_{80}$ & $\mathrm{P}_{80}$ \\
\hline & $\mathrm{W}_{0 \cdot 2 \mathrm{x}}$ & $\mathrm{W}_{0 \cdot 2 \mathrm{x}}$ & $\ldots$ & $\mathrm{P}_{90}$ & $\mathrm{P}_{90}$ \\
\hline & $\mathrm{W}_{0 \cdot 1 \mathrm{x}}$ & $\mathrm{W}_{0 \cdot 1 \mathrm{x}}$ & $\ldots$ & $\mathrm{P}_{100}$ & $\mathrm{P}_{100}$ \\
\hline reduction degree & 0 & 10 & $\ldots$ & 90 & 100 \\
\hline
\end{tabular}

Table I

Rankings of gradient constraints and resulting patterns of reduction, based on Jun (2004).

maintaining a given percentage of place of articulation information (in increasing order) and registers $\mathrm{A}-\mathrm{K}$ represent a continuum from the slowest/most formal register to the fastest/most informal register (based on Jun 2004: 80f). Different rankings of the constraints result in different degrees of reduction of articulatory gestures, increasing from register $\mathrm{A}$ to register K. Relevant parts are shaded. For example, in register B the constraint $\mathrm{W}_{1 \mathrm{x}}$ ('do not produce a gesture whose effort cost is 1 ') is ranked above the constraint $\mathrm{P}_{100}$ ('preserve at least $100 \%$ of cues to place'), but below the constraint $\mathrm{P}_{90}$ ('preserve at least $90 \%$ of cues to place'). This will result in a $10 \%$ reduction of the articulatory gesture. That is, the affected gesture is produced only partially, without a complete constriction being made (e.g. an incomplete constriction of the Tongue Tip at the alveolar ridge for $/ t /$ ). Jun's assumptions about the gradient implementation of Korean place assimilation are based on his experimental findings for labial reduction in $/ \mathrm{pk} /$ (Jun 1996). His study, however, did not examine assimilation in the coronal-initial sequences $/ \mathrm{tp} /$ and $/ \mathrm{tk} /$.

In sum, Jun's account of Korean place assimilation is different from other previous accounts in the sense that it attempts to capture both obligatory/categorical and variable/gradient aspects of the process through the introduction of stochastic, register-specific rankings and gradient constraints. This approach is not uncontroversial, as questions 


\section{Alexei Kochetov and Marianne Pouplier}

remain about the necessity of incorporating functional teleologies in the grammar (Pouplier 2003, Blevins 2004, 2007) and about adequate ways of modelling the mapping between continuous and discrete aspects of speech (e.g. Gafos 2006, Scobbie 2007). Independently of this, however, Jun's formalisation of Korean place assimilation yields testable hypotheses about patterns, types and relative frequencies of gestural reduction to be found in actual speech data. It will therefore serve as a point of reference for our experimental results. We return to some of the remaining questions at the end of the paper.

\subsection{Predictions}

Assuming that the patterns of place assimilation exhibited by native speakers of Korean reflect the rankings of the grammatical constraints outlined above, we can predict the following. With respect to variability, in fast speech Korean speakers are expected to reduce the Tongue Tip gesture of $/ \mathrm{t} /$ in $/ \mathrm{tp} /$ and $/ \mathrm{tk} /$ and the Lip gesture of $/ \mathrm{p} /$ in $/ \mathrm{pk} /$ (given the ranking Weakening $\gg \operatorname{Pres}(\operatorname{pl}[\operatorname{cor}]), \operatorname{Pres}(\mathrm{pl}[\mathrm{lab}])$ in (6)), but not in slow speech (Pres(pl[cor]), Pres(pl[lab]) $\gg$ Weakening). Overall, rates of reduction should not differ substantially for $/ \mathrm{p} /$ and $/ \mathrm{t} /$ (given that $\operatorname{Pres}(\mathrm{pl}[\mathrm{lab}])$ and $\operatorname{PrEs}(\mathrm{pl}[\mathrm{cor}])$ are in the same ranking stratum). Similarly, rates of reduction of $/ \mathrm{t} / \mathrm{in} / \mathrm{tp} /$ and $/ \mathrm{tk} /$ should not differ substantially from each other (given that both sequences are referred to by the same ranking Weakening $\gg \operatorname{PrEs}(\mathrm{pl}[\mathrm{cor}])$ ). Further, rates of reduction should overall be similar within words and across words (given that the constraint rankings do not refer to boundaries). Finally, no reduction of $/ \mathrm{p} /$ and $/ \mathrm{k} /$ in the sequences $/ \mathrm{pt} /, / \mathrm{kt} /$ and $/ \mathrm{kp} /$ is expected, regardless of the speech rate $(\operatorname{Pres}(\mathrm{pl}[\mathrm{dors}]), \operatorname{Pres}(\mathrm{pl}[$ _ cor $]) \gg$ Weakening $)$. With respect to the phonetic realisation of the Tongue Tip and Lip gestures in $/ \mathrm{tp} /, / \mathrm{tk} /$ and $/ \mathrm{pk} /$, we would expect to find a continuum of values, from no reduction through various degrees of partial reduction to complete reduction. An increase in speech rate should lead to greater degrees of gestural reduction, with the fastest rate resulting in predominantly categorical reduction (given the register-dependent rankings of the gradient PRESERVE and Weakening constraints in Table I). Overall, the patterns of gradient/ categorical reduction should not differ substantially (i) between $/ \mathrm{p} /$ and $/ \mathrm{t} /$, (ii) between $/ \mathrm{tp} /$ and $/ \mathrm{tk} /$ and (iii) between words and across words (given the same rankings of the respective constraints, as noted above). Finally, a reduction of the coronal gesture in $/ \mathrm{tp} /$ and $/ \mathrm{tk} /$ should be accompanied by temporal extension of the following labial or dorsal gesture (see (4)).

In this paper, we test all these predictions experimentally. In $\$ 3$ we present an experiment designed to investigate the reduction of coronals as targets (in $/ \mathrm{tp} /$ and $/ \mathrm{tk} /$ ), as well as the lack of reduction of non-coronals in non-assimilating sequences $(/ \mathrm{pt} /, / \mathrm{kt} /$ and $/ \mathrm{kp} /)$. In $\S 4$ we review the results of an experiment by Son et al. (2007) investigating the reduction of labials as targets (in $/ \mathrm{pk} /$ ) in Korean. 


\section{Coronals as targets}

\subsection{Method}

Three native speakers of the Seoul dialect of Korean, two males (K1 and K3) and one female (K2), participated in the experiment. All subjects were unaware of the purposes of the experiment. Experiment materials consisted of 'target' and 'control' items. Target items included words and phrases with sequences of coronal stops as C1 and labial or velar stops as C2 (7a). These sequences were expected to be pronounced variably as a function of speaking rate, either with a fully articulated $[t]$ or with various degrees of reduction of the tongue-tip gesture, including its categorical deletion. Control items included words and phrases with coronals that were not expected to be reduced or deleted (7b), or words and phrases without coronals $(7 \mathrm{c})$. Note that some correspondences between underlying and surface consonants are obscured by other processes. Recall that underlying aspirated stops, affricates and /s/ surface in coda position as plain voiceless unreleased stops at the same place of articulation; plain voiceless stops become fortis when preceded by stops (see $\$ 2.1$ ). In addition, non-coronal $\mathrm{C} 1$ consonants in the non-assimilating sequences $/ \mathrm{pt} /, / \mathrm{kt} /$ and $/ \mathrm{kp} /$ were examined for reduction (cf. the relevant stimuli in $(7 \mathrm{~b}-\mathrm{d})$ ). Two prosodic conditions, words and phrases, were used to determine whether place assimilation applies similarly in the two contexts. Preceding and following vowels were the same throughout the target and control items $(/ \mathrm{a} /){ }^{2}{ }^{2}$ The following list represents the full set of stimuli used in the current study.

(7) a. Target words/phrases with coronal $\mathrm{C} 1$

/kas-pay/

/kas pak'uəsə/

/pas-kalak/

/pat kamcən-ha-mjə/ [tp'] [pp']

$[\mathrm{tp}] \sim[\mathrm{pp}] \quad$ 'after changing hats'

[tk'] [kk'] 'toes (archaic)'

[tk'] [kk'] 'estimating a dry field's value'

b. Control words/phrases 1 (including a tongue-tip gesture)

\begin{tabular}{|c|c|c|}
\hline $\begin{array}{l}\text { /hap-tay/ } \\
\text { /hap tayki-mjənsə/ } \\
\text { /mak-tambe/ } \\
\text { /mak tajay-ha-ke/ }\end{array}$ & $\begin{array}{l}{\left[\mathrm{pt}^{\prime}\right]} \\
{\left[\mathrm{pt}^{\prime}\right]} \\
{\left[\mathrm{kt}{ }^{\prime}\right]} \\
{\left[\mathrm{kt} \mathrm{kt}^{\prime}\right]}\end{array}$ & $\begin{array}{l}\text { 'a merger of political parties' } \\
\text { 'pulling the sum' } \\
\text { 'a bad quality cigarette' } \\
\text { 'carelessly' }\end{array}$ \\
\hline \multicolumn{3}{|c|}{ Control words/phrases 2 (no tongue-tip gesture) } \\
\hline$/ \mathrm{ap}^{\mathrm{h}}-\mathrm{pal} /$ & [pp'] & 'a front paw' \\
\hline /aph palapo-ko/ & [pp'] & 'to look forward and' \\
\hline /ak-kam-cəy/ & {$[\mathrm{kk}$} & 'hatred' \\
\hline /ak katatim-ko/ & {$\left[\mathrm{kk}^{\prime}\right]$} & 'to renew spirit and' \\
\hline \multicolumn{3}{|c|}{ Target words/phrases with velar $\mathrm{C} 1$} \\
\hline |ak-pali/ & [kp’] & 'a tough fellow' \\
\hline /ak pala-mjənsə/ & [kn'] & 'wishing evil' \\
\hline
\end{tabular}

2 The need to control for vowel context led to the inclusion of some uncommon words, such as /pas-kalak/ 'toes'. 


\section{Alexei Kochetov and Marianne Pouplier}

All target and control items were presented randomly in a carrier phrase /neka__lanin malil tiləpoas'ta/ ('I have heard of _') for K1 and (to shorten the carrier phrase and thus reduce experiment time)/neka_lako tiləs'a/ ('I heard it as_') for subjects K2 and K3. On average, nine repetitions of each target word or phrase were collected. Since place assimilation in Korean has been noted to correlate with speech rate or register, we employed two speaking rate conditions: subjects were instructed to read the sentences at a normal, comfortable rate ('slow rate') or quickly ('fast rate'). A total of 60 target utterances were collected for speaker K1 $(2$ sequences $\times 2$ boundary contexts $\times 2$ speech rates $\times 7$ or 8 repetitions), and 72 target utterances were collected for speakers K2 and K3 ( 2 sequences $\times 2$ boundary contexts $\times 2$ speech rates $\times 9$ repetitions).

Articulatory movement data were collected with the electromagnetic midsagittal articulometer (EMMA; Perkell et al. 1992) at Haskins Laboratories. The apparatus allows the tracking of individual fleshpoints by means of small transducer coils attached to various points on the subject's vocal tract in the midsagittal plane. The details of the EMMA procedure and measurements are described in the Appendix. Using a classification metric based on the statistical distribution of the controls (also detailed in the Appendix) all tokens were labelled as unreduced, fully reduced or partially reduced. Reduction rate (percentage of all reduced tokens) was computed for each of the experimental conditions: context, boundary and speaking rate. These data were examined statistically using an ANOVA with the dependent variable Reduction Rate and the fixed factors Sequence (two levels: $/ \mathrm{tp} /$ and $/ \mathrm{tk} /$ ), Boundary (two levels: word and phrase) and Speaking Rate (two levels: slow and fast), performed separately for each subject. Significance level was set at 0.05. Further, partially reduced tokens in each subject's productions were examined for degrees of reduction, and compared to fully reduced and unreduced tokens.

\subsection{Results}

We will first examine the results for the reduction rate for $/ t \mid$, our measure of variable application of the process, followed by the results for gradient/ complete realisation of coronal targets. Finally, we will examine the phonetic realisation of non-coronals in non-assimilating sequences.

3.2.1 Variable application. Reduction rate results for $/ \mathrm{t} /$ are plotted in Fig. 1 by speaker, Sequence and Boundary condition, for slow (a) and fast (b) speaking rate. Note that all three speakers exhibited gestural reduction in most conditions, with overall higher rates of reduction for $\mathrm{K} 1$ ( $89 \% ; 53$ tokens) and $\mathrm{K} 3(71 \%$; 51 tokens) than for K2 (17\%; 12 tokens). The subjects showed higher reduction rates in $/ \mathrm{tp} /$ than in $/ \mathrm{tk} /$ within words; $\mathrm{K} 1$ and $\mathrm{K} 3$ had higher reduction rates in phrases than in words for $/ \mathrm{tk} /$. Reduction rate was somewhat higher in fast speech than in slow speech. 
(a)

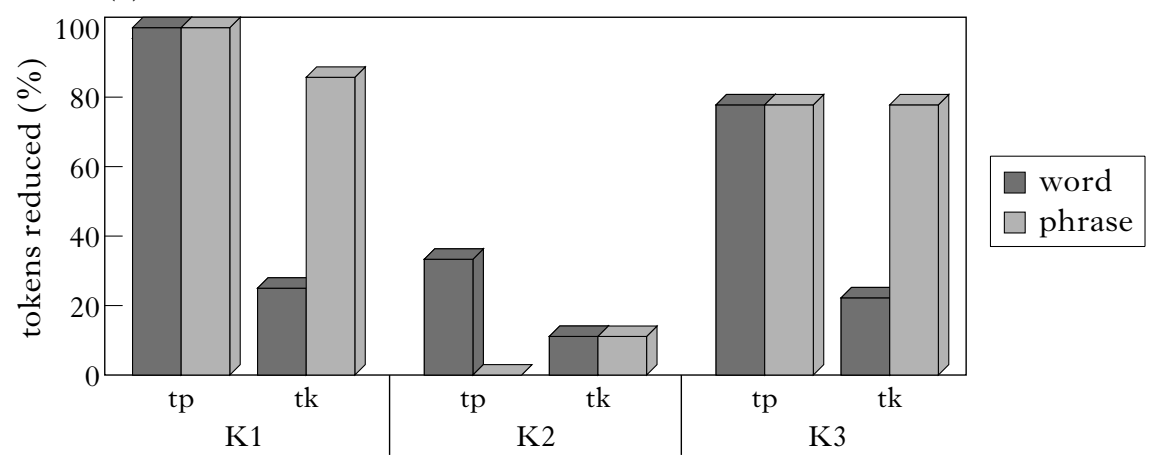

(b)

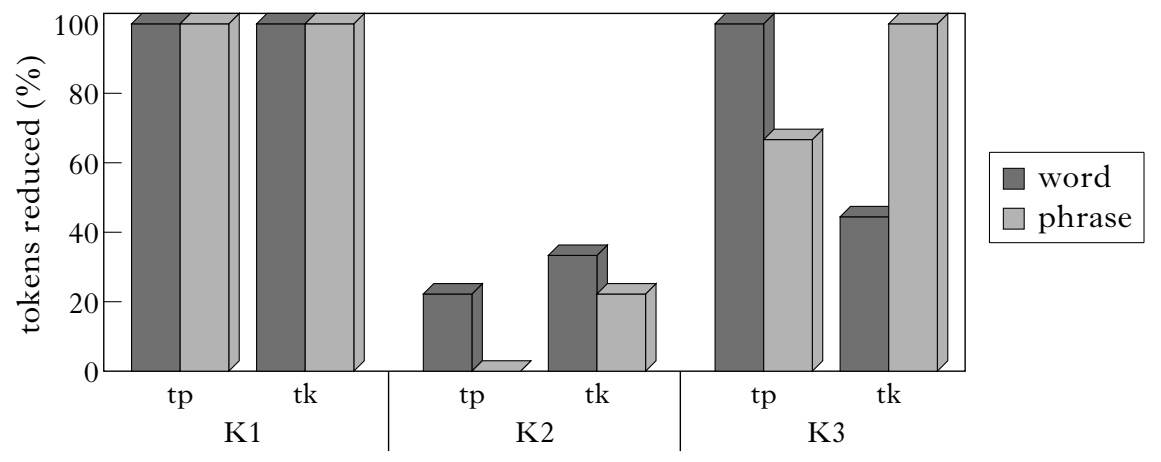

Figure 1

Reduction rate ( $\%)$ for the coronal gesture by consonant sequence, boundary condition and subject, by slow (a) and fast (b) speaking rate.

ANOVA results revealed a significant effect of Sequence for K1 and K3 $(\mathrm{F}(1,60)=16 \cdot 414, \mathrm{p}<0 \cdot 001 ; \mathrm{F}(1,72)=4 \cdot 170, \mathrm{p}<0 \cdot 05)$ : there was more reduction in $/ \mathrm{tp} /$ than in $/ \mathrm{tk} /$. There was a significant effect of Boundary for both $\mathrm{K} 1$ and $\mathrm{K} 3(\mathrm{~F}(1,60)=7 \cdot 590, \mathrm{p}<0 \cdot 01 ; \mathrm{F}(1,72)=4 \cdot 170$, $\mathrm{p}<0.05)$ : they showed greater reduction in phrases than in words. Speaking Rate was significant only for K1 (fast $>$ slow; $F(1,60)=16 \cdot 414$, $\mathrm{p}<0 \cdot 001)$. The results for this subject also showed a significant three-way interaction of Sequence $\times$ Boundary $\times$ Speaking Rate $(F(1,60)=7 \cdot 590$, $\mathrm{p}<0 \cdot 01)$. The interaction indicated that significant boundary and sequence differences for this subject were limited to the fast speaking rate, and speaking rate differences were limited to the $/ \mathrm{tk} /$ sequence (given the overall $100 \%$ reduction rate in $/ \mathrm{tp} /$ ). No significant differences in reduction rate were found for K2, likely due to the overall small number of reduced tokens for this subject. The different performance of K2 was also possibly related to the speaker's more careful and slower speaking rate throughout the experiment. However, measurements of overall duration 
412 Alexei Kochetov and Marianne Pouplier

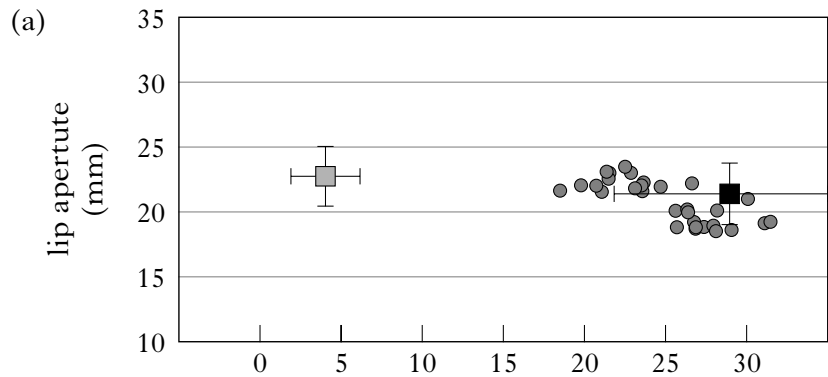

- tp

$\square$ pt mean

- pp mean

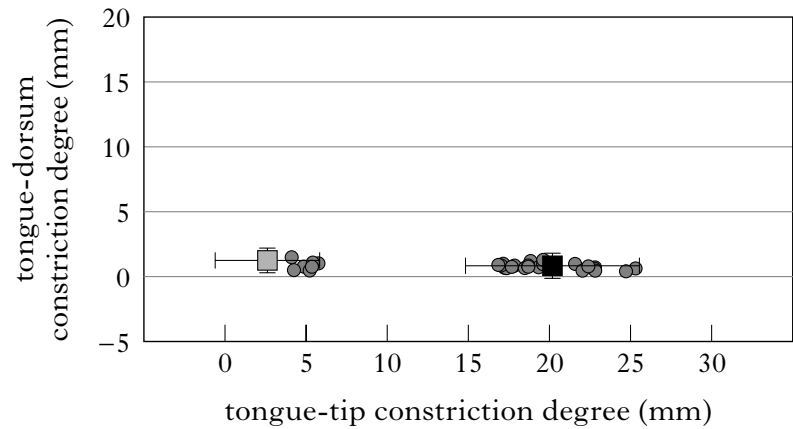

o tk

$\square \mathrm{kt}$ mean

- kk mean

speaker K1

(b)

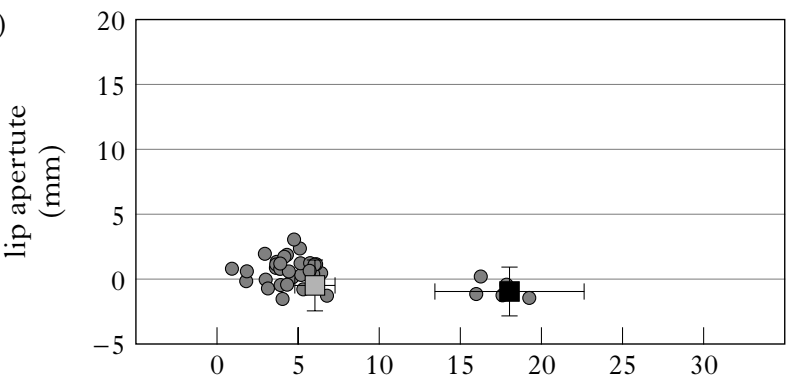

o tp

$\square$ pt mean

- pp mean

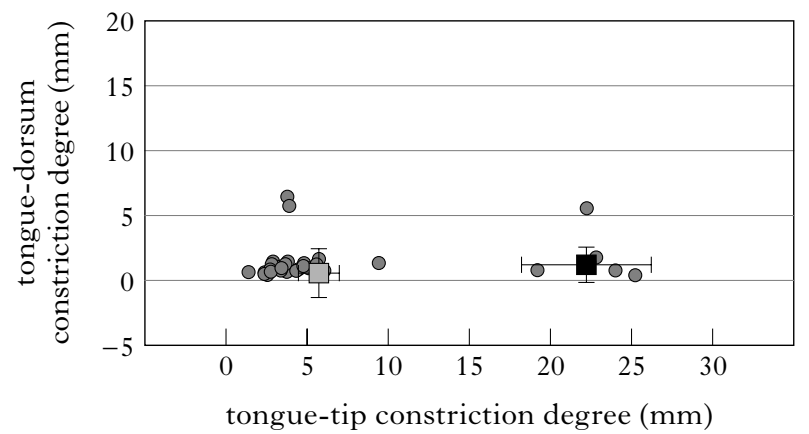

o $\mathrm{tk}$

$\square \mathrm{kt}$ mean

- kk mean 
(c)

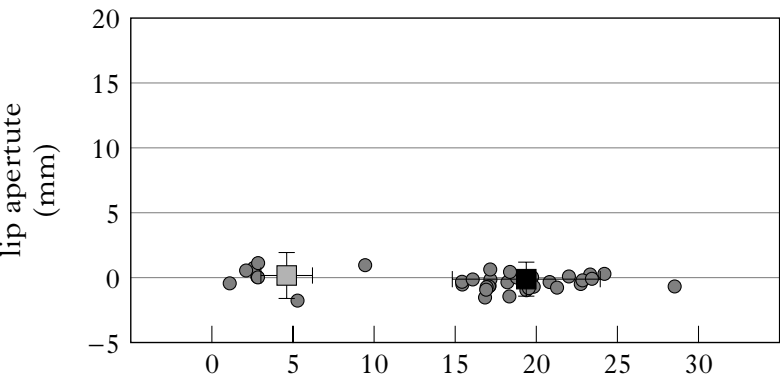

$\circ$ tp

$\square$ pt mean

- pp mean
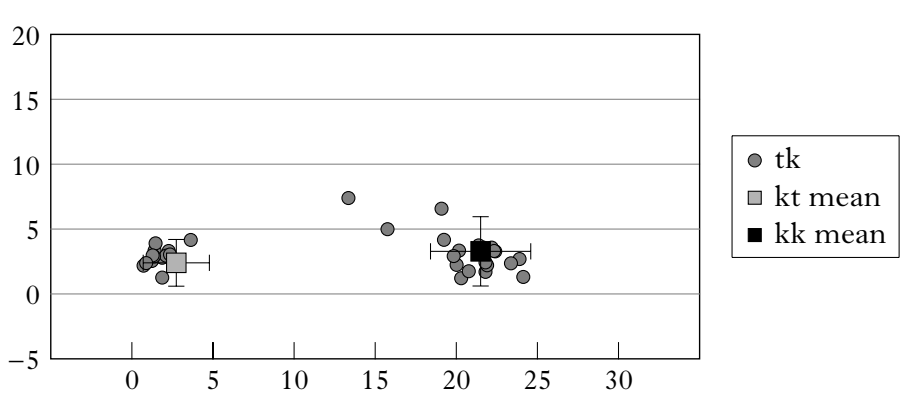

tongue-tip constriction degree $(\mathrm{mm})$

speaker K3

Figure 2

Scatterplots for all individual $/ \mathrm{tp} /$ and $/ \mathrm{tk} /$ tokens, for speakers K1 (a), K2 (b) and K3 (c). A constriction degree approximating zero indicates closure, as expected for a stop consonant. Error bars show two standard deviations from the mean.

of slow and fast utterances confirmed that there was a difference between the two speaking rate conditions: for all three subjects slow utterances were significantly longer than fast utterances $(\mathrm{K} 1: \mathrm{t}(27)=10 \cdot 93, \mathrm{p}<0.001$; $\mathrm{K} 2: \mathrm{t}(35)=6 \cdot 838, \mathrm{p}<0 \cdot 001 ; \mathrm{K} 3: \mathrm{t}(35)=12 \cdot 496, \mathrm{p}<0 \cdot 001) .{ }^{3}$ Idiosyncratic between-subject differences in frequency and degree of assimilation have previously been found in some studies on assimilation in English, for example Ellis \& Hardcastle (2002; cf. also Scobbie et al. 2007), and we will come back to this aspect of our data in the discussion.

3.2.2 Gradient/categorical implementation. Most of the reduced / $/ \mathrm{t}$ tokens were classified as 'fully reduced'. Only eleven tokens were classified as 'partially reduced' $(9 \cdot 5 \%$ of all reduced tokens and $5 \%$ of all tokens). Figure 2 displays the tongue-tip constriction degree (TTCD)

3 Duration was measured between the tongue-tip maxima of the first coronal consonant in [neka] and the last coronal consonant in [tiləpoata] or [tiləs'ə] of the carrier phrases of slow and fast utterances with $/ \mathrm{tp} /$ and $/ \mathrm{tk} /$ within words and across words for each of the speakers. 


\section{Alexei Kochetov and Marianne Pouplier}

values for reduced and unreduced $/ \mathrm{tp} /$ and $/ \mathrm{tk} /$ tokens separately for each speaker. The means are displayed with two standard deviation error bars, indicating the threshold values used to categorise the tokens as 'unreduced', 'partially reduced' and 'fully reduced' (see Appendix). For example, it can be seen (Fig. 2c) that all /tp/tokens produced by K3 were reduced, since they were above two standard deviations from the control TTCD value for $/ t /$; among the reduced tokens, seven were classified as gradiently reduced, falling between the TTCD values of both control distributions; the other 23 tokens were classified as categorically reduced, since they were within the range of TTCD variation found for $/ p /$. Note also that the partially reduced tokens produced by this speaker did not span the 'gradiently reduced' range, but rather clustered close to the 'fully reduced' threshold. With respect to /tk/, the same speaker had either unreduced or fully reduced tokens (that is, either below or above the respective threshold values). Only one token of speaker K2 (Fig. 2b) was classified as partially reduced (among the very few reduced tokens). Note also that this token is only $1.5 \mathrm{~mm}$ above the 'unreduced' threshold value. The three partially reduced tokens of speaker K3, however, do show values intermediate between the unreduced and fully reduced thresholds. Overall, there was no clear correlation between partial reduction and the speech rate or boundary conditions: all of the partial tokens of K1 occurred at the fast rate, both within words and across words, whereas the partial token of $\mathrm{K} 2$ occurred across words at the slow rate, two of the partial tokens of $\mathrm{K} 3$ occurred within words at the fast rate, while the other token occurred across words in the slow rate condition.

The examination of the reduced tokens confirmed that the subjects tended to exhibit a binary mode of tongue-tip reduction: either no reduction at all or full reduction (categorical assimilation). Gradient (partial) implementation of the process was an option, yet clearly a marginal one.

To examine whether reduction of the coronal gesture was accompanied by temporal extension of the following labial or dorsal gesture, measurements of the lip-aperture and tongue-dorsum constriction duration were made for the reduced tokens of $/ \mathrm{tp} /$ and $/ \mathrm{tk} /$, as well as for all tokens of $/ \mathrm{pp} /$. The results, summarised in Fig. 3, showed somewhat different patterns for the two sequences. (Note that no data were available for some speaking rate and boundary conditions for K1 and K2.) Overall, the labial constriction was considerably shorter in reduced $/ \mathrm{tp} /$ than in $/ \mathrm{pp} /$ (except within words for $\mathrm{K} 1$ and in slow rate for K2), suggesting that gestural reduction of $\mathrm{C} 1$ was not accompanied by a full extension of $\mathrm{C} 2$. The dorsal constriction in reduced $/ \mathrm{tk} /$, however, was about as long as in $/ \mathrm{kk} /$ (except for slow words for K1 and K2), suggesting that gestural extension did take place. To the extent that measures of duration can be used at all to distinguish deletion from assimilation, it appears that the process was realised as deletion in some cases and as assimilation in other cases (similar difficulties in distinguishing deletion and assimilation in articulatory data have been noted by Nolan et al. 1996 for English and Kühnert \& Hoole 2004 for German). 
(a)

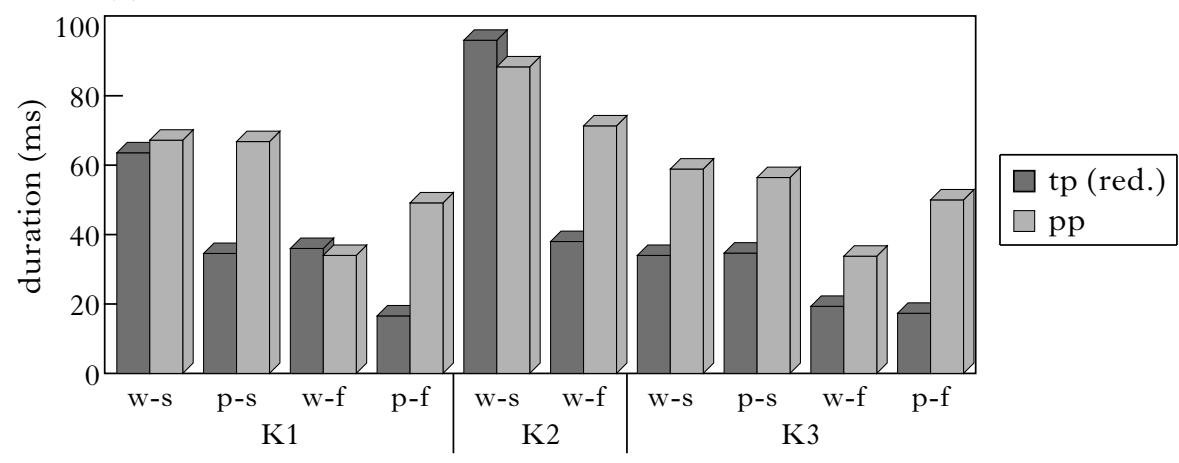

(b)

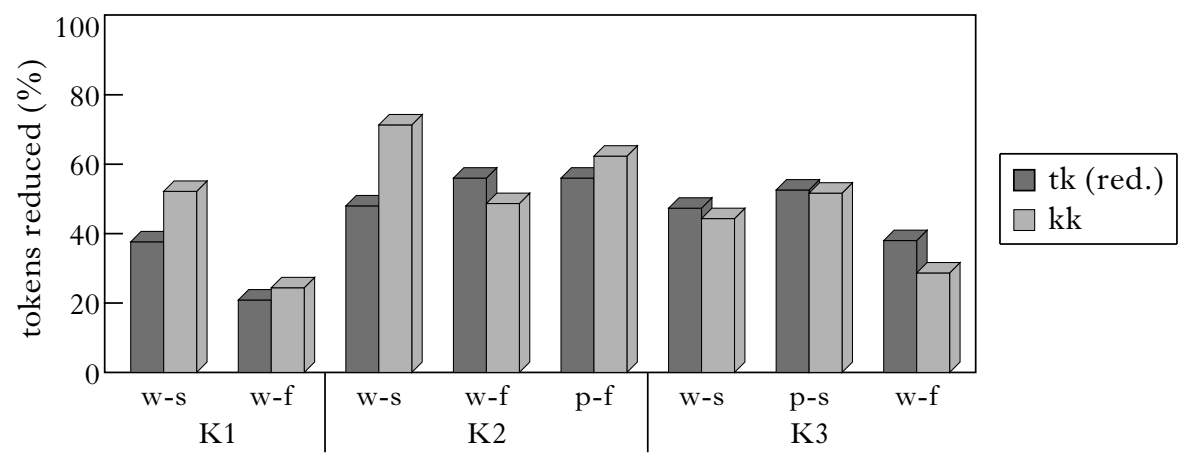

Figure 3

Duration (in ms) of Lip Aperture constriction in reduced / $\mathrm{tp} /$ vs. $/ \mathrm{pp} /$ (a) and in reduced $/ \mathrm{tk} /$ vs. $/ \mathrm{kk} /(\mathrm{b})$, by speaker, boundary (word and phrase) and speaking rate (slow and fast).

3.2.3 Non-assimilating sequences. Most of the $/ \mathrm{p} /$ and $/ \mathrm{k} /$ tokens in $/ \mathrm{pt} /$, $/ \mathrm{kt} /$ and $/ \mathrm{kp} /$ sequences were classified as unreduced; there were no fully reduced tokens. 18 tokens were classified as gradiently reduced ( $6 \%$ of all tokens). For K1, these included one token of $/ \mathrm{pt} /$ (phrase; fast), two tokens of $/ \mathrm{kt} /$ (phrase; fast and slow) and five tokens of $/ \mathrm{kp} /$ (phrase and word; fast). All these tokens, however, were no more than $1 \mathrm{~mm}$ away from the reduction threshold, and thus may not be 'truly gradient' cases; they will not be included in the further discussion. No reduced tokens were found for K2. For K3, there were two gradiently reduced tokens of $/ \mathrm{pt} /$ (phrase; slow) and eight tokens of $/ \mathrm{kp} /$ (phrase and word; fast and slow). While the $/ \mathrm{pt} /$ tokens were within $1 \mathrm{~mm}$ of the gradient reduction threshold, values for most $/ \mathrm{kp} /$ tokens were at least $2 \mathrm{~mm}$ away, with one token almost $5 \mathrm{~mm}$ away from the categorical threshold (and $3.5 \mathrm{~mm}$ from the categorical reduction threshold). At least some of these tokens, therefore, may be regarded as 'truly gradient' cases. This is shown in Fig. 4, which plots all $/ \mathrm{kp} /$ tokens for the speaker K3. 


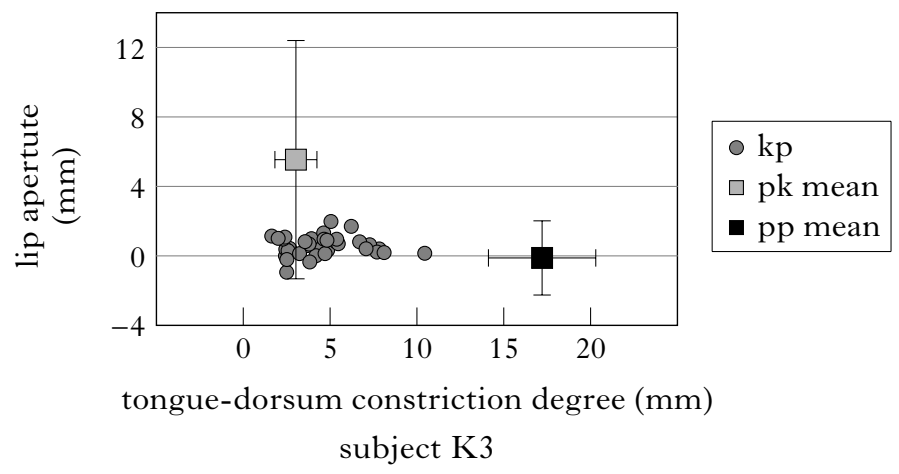

Figure 4

Individual $/ \mathrm{kp} /$ tokens produced by speaker $\mathrm{K} 3$ and control (/pk kk/) means.

Error bars indicate two standard deviations. A constriction degree approximating zero indicates closure, as expected for a stop consonant. The /pk/ control mean has a very large standard deviation in Lip Aperture, since for some tokens $/ p /$ is reduced. Since our measurements concern only comparisons of tongue dorsum constriction degree, this is of no further relevance at this particular point in the paper.

\subsection{Discussion}

The results showed that the overall reduction rate of coronals as targets was highly variable both within and across speakers' productions. At least for two speakers, it was sensitive to Sequence $(/ \mathrm{tp} /$ vs. $/ \mathrm{tk} /)$ and Boundary (word vs. phrase). Reduction occurred at both speaking rates, although there was more reduction at the fast rate. In the majority of cases, assimilated gestures were categorically reduced, yet some gradiently reduced gestures were also observed for all three speakers. There was no clear relation between gradient/categorical realisation of reduced tokens and speaking rate. While some of the variability in the implementation of non-coronal gestures in non-assimilating sequences can hardly qualify as gradient reduction, there were a few clearly gradient cases of dorsal reduction in $/ \mathrm{kp} /$ produced by one of the speakers. Finally, while in some cases the reduction of the coronal gesture was accompanied by an extension of the gesture of the following consonant (resulting in $\mathrm{C} 1$ assimilation to $\mathrm{C} 2$ ), in other cases no such extension was observed (resulting in $\mathrm{C} 1$ deletion).

How do these results match our predictions outlined in $\$ 2.3$ ? While the overall variable application of coronal reduction was expected on the basis of Jun's $(1995,2004)$ account, the sensitivity of the process to the experimental variables Sequence and Boundary was not expected. Some gradience found in the implementation of the coronal gesture provides support for the account. However, gradient implementation was clearly a marginal strategy for our speakers. Instead of the expected full range of degrees of reduction and rate-specific realisations, most of the tokens 
were either fully reduced (categorically assimilated) or not reduced. Finally the finding of partial reduction of $/ \mathrm{k} /$ in $/ \mathrm{kp} /$ (at least for one speaker) is completely unexpected, as velars in Korean have been described as being immune to assimilation. While this finding will need to be confirmed in further experiments, it suggests that gradient reduction may apply in sequences that are not normally considered to be contexts for place assimilation. It may also be the case that velar reduction in $/ \mathrm{kp} /$ is part of a more general coda-reduction process, not yet understood. The finding that coronal reduction is not always accompanied by labial or dorsal extension, potentially indicative of a deletion rather than an assimilation process, is also in contrast with Jun's account (cf. (4)) and previous phonological treatments of the process (Kim-Renaud 1991, Ahn 1998). Note that the lack of a temporal extension of C2 was also found for some English speakers in Ellis \& Hardcastle's (2002) study (for a note of caution regarding the use of duration measurements to uncover the nature of underlying assimilatory processes, see Kühnert \& Hoole 2004).

The significant Sequence effect may be interpreted in the context of studies on other languages which have uncovered a place of articulation asymmetry in the overlap patterns of stop-stop sequences (Byrd 1996, Chitoran et al. 2002, Kochetov et al. 2007). This means that in stop-stop sequences, a back-to-front order in terms of place of articulation (e.g. /tp/) displays less overlap than a front-to-back order (e.g. /pt/). This effect has been ascribed to perceptual recoverability requirements: front-to-back sequences will be recoverable even when overlapped substantially, yet in back-to-front sequences $\mathrm{C} 1$ may be completely obscured by $\mathrm{C} 2$. We were also able to confirm the existence of the asymmetry in overlap patterns for our current Korean data (see Kochetov et al. 2007). ${ }^{4}$ While our data suggest a connection between asymmetries in overlap and those in reduction patterns, further research will need to show whether such covariation truly exists.

Similarly, the Boundary difference observed in the current study can potentially be interpreted in the light of a study by Tiede et al. (2007) on gestural phasing in English $/ \mathrm{kt} /$ sequences within (pact op) and across ( $p a c k$ top) words. The authors observed that relative phasing in $/ \mathrm{kt} /$ sequences remained relatively invariant tautosyllabically as compared to across word boundaries. If the dorsal and coronal gestures of $/ \mathrm{kt} /$ are in a closer phasing relationship with each other within a word/syllable than across word boundaries (cf. Byrd 1996), a greater temporal overlap of the articulator movement within a word may conceivably condition a greater influence of tongue-dorsum behaviour on tongue-tip movement compared to across words. However, the interaction between temporal

${ }^{4}$ However, recent results from other languages have challenged the interpretation that overlap asymmetries may be caused by recoverability constraints (Chitoran \& Goldstein 2006, Kühnert et al. 2006). Kühnert et al. (2006), for instance, highlight the role of inherent constraints on tongue movement. The origins of asymmetries in gestural overlap patterns may thus be manifold, and also language-specific. 


\section{Alexei Kochetov and Marianne Pouplier}

overlap and spatial reduction remains a topic of much discussion (Jun 1996, Chen 2003), and an issue for future research. It should be noted that Sequence and Boundary effects on reduction rate may be confounded by relative word frequency or familiarity (as, for example, in the case with the less familiar word / patkalak/). These factors could not be controlled for in the current experiment and are therefore left for further investigation.

Finally, the relation between coronal place assimilation and accentual phrasing was not investigated in the current study, given that accentual phrasing was not found to be a factor in the study of labial place assimilation (as discussed at the end of $\S 4$ ).

\section{Labials as targets}

In this section we review the main results on the assimilation of labials in $/ \mathrm{pk} /$ sequences reported in Son et al. (2007), and discuss them with respect to the predictions outlined in $\$ 2.3$.

Experiment materials, target and control words and phrases, are shown in (8). Data collection and analysis procedures were exactly the same as outlined in $\$ 3.1$. The same subjects participated and the data were recorded in the same session.

(8) a. Target words/phrases

/aph-kalim/ [pk'] [kk'] 'a sense of what is good for oneself' /ap ${ }^{\mathrm{h}} \mathrm{kalik}^{\mathrm{h}} \mathrm{i}-\mathrm{ko} / \quad\left[\mathrm{kk}^{\prime}\right] \sim\left[\mathrm{kk}^{\prime}\right] \quad$ 'to point forward and'

b. Control words/phrases

\begin{tabular}{|c|c|c|}
\hline $\begin{array}{l}\text { /ap }{ }^{\mathrm{h}}-\mathrm{pal} / \\
\text { /ap palapo-ko/ } \\
\text { /ak-kam-cəy/ } \\
\text { /ak katatim-ko/ }\end{array}$ & $\begin{array}{l}{\left[\mathrm{pp}{ }^{\prime}\right]} \\
{\left[\mathrm{pp}{ }^{\prime}\right]} \\
{[\mathrm{kk}]} \\
{[\mathrm{kk}]}\end{array}$ & $\begin{array}{l}\text { 'a front paw' } \\
\text { 'to look forward and' } \\
\text { 'hatred' } \\
\text { 'to renew spirit and' }\end{array}$ \\
\hline
\end{tabular}

Figure 5a plots reduction rates for the labial gesture in $/ \mathrm{pk} /$ by speaker, Sequence and Boundary condition, separately by slow (a) and fast (b) speaking rate. Note that all three subjects showed at least some labial reduction within words, greater overall for K1 (41\%) and K3 $(33 \%)$ than for K2 $(3 \%)$. None of the subjects reduced the labial gesture across words. Reduction rate within words was higher at fast speaking rate than at slow speaking rate. An examination of reduced tokens showed that the lip gesture in all of them was completely reduced, i.e. the target $/ \mathrm{p} /$ was categorically assimilated to $/ \mathrm{k} /$ (see Son et al. 2007 for details).

Similarly to our findings for coronal reduction, the results for labial reduction exhibited considerable within- and across-speaker variability. Overall, the rate of labial reduction was lower than for coronal reduction, partly due to the complete lack of labial reduction across word boundaries. This difference between coronals and labials as 
(a)

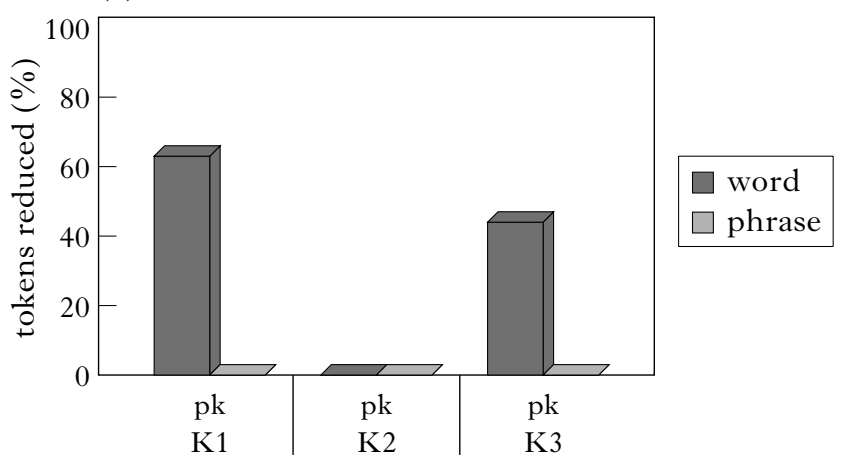

(b)

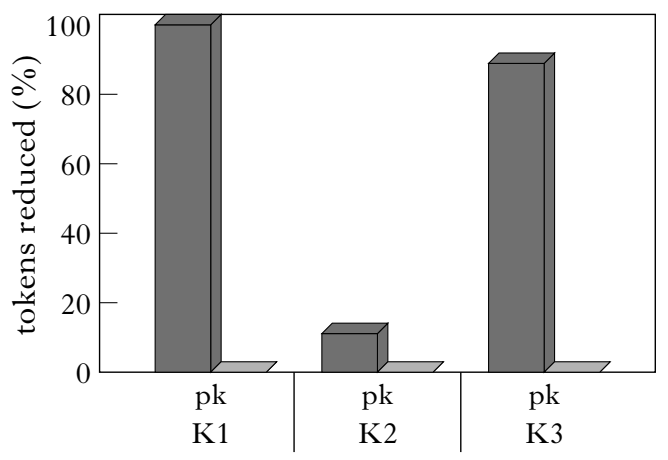

Figure 5

Reduction rate (\%) for the labial gesture by consonant sequence, boundary condition and subject, by slow (a) and fast (b) speaking rate.

targets of assimilation and the sensitivity of labial reduction to boundaries are at odds with our predictions formulated in $\$ 2.3$. Further, the speakers' realisations of reduced gestures were consistently categorically reduced (assimilated $[\mathrm{kk}]$ ), contrary to the predictions and in contrast with the possible (albeit infrequent) gradient implementation of reduced coronals. These results are therefore indicative of asymmetries between coronal and labials in the speakers' grammars that are not captured by Jun's account.

It is known that segmental processes in Korean may be sensitive to accentual phrasing (Jun 1993, 1998). The lack of labial assimilation across the word boundary in $/ \mathrm{ap}^{\mathrm{h}} \mathrm{kalik}^{\mathrm{h}} \mathrm{kko} /$ could, therefore, be attributed to an accentual phrase boundary between $/ \mathrm{p}^{\mathrm{h}} /$ and $/ \mathrm{k} /$. However, auditory transcription and an acoustic analysis performed by two phoneticians, both native speakers of Korean, revealed no clear relationship between labial reduction and presence of absence of accentual phrase boundary (see Son et al. 2007 for details). 


\section{Alexei Kochetov and Marianne Pouplier}

\section{General discussion}

The results of the EMMA studies of Korean coronal and labial place assimilation reported in this paper have confirmed some previous general observations with respect to the targets of assimilation, its variable status and the possibility of gradient realisation. At the same time, the results show that the process as exhibited by our speakers is in many respects more fine-grained than previous descriptions suggest, even the most detailed accounts (Jun 1995, 2004). First, the process of place assimilation can refer to specific segmental contexts: $/ \mathrm{t} /$ assimilates to $/ \mathrm{p} /$ more frequently than to $/ \mathrm{k} /$. Second, the process applies differently within words and across words: this is manifested in different rates of reduction (with more reduction in the word-boundary condition for $/ \mathrm{pk} \mathrm{tk} /$ and variable results for $/ \mathrm{tp} /$ ), as well as in different phonetic realisations in the two environments. Third, labials and coronals behave, contrary to our expectations, differently with respect to assimilation rate, the application of the process across word boundaries, and its phonetic realisation. Our speakers did not assimilate $/ \mathrm{p} /$ to $/ \mathrm{k} /$ across word boundaries, but did assimilate within words; $/ \mathrm{t} /$, however, assimilated to $/ \mathrm{p} /$ and $/ \mathrm{k} /$ both within words and across words. While coronals were sometimes gradiently reduced, the reduction of labials was always categorical. Gestural reduction of coronals was not always accompanied by the gestural extension of following consonants. Fourth, at least some speakers showed gradient reduction of gestures in contexts that have not been previously described as assimilation sites (e.g. dorsal reduction in $/ \mathrm{kp} /$ by K3). Finally, the three speakers were consistent in some general aspects of their productions, for example, in the expected lack of assimilation of $/ \mathrm{p} /$ and $/ \mathrm{k} /$ before coronals, and in the variable assimilation of $/ \mathrm{t} /$ and $/ \mathrm{p} /$ within words. At the same time, the speakers differed considerably in other, more specific properties of the process: rates of assimilation, reference to segmental contexts and phonetic manifestation of assimilated consonants. This suggests that the speakers' grammars of place assimilation agree at a more general, 'macroscopic', level, but vary at a more specific, 'microscopic', level.

The overall degree of within- and across-speaker variability in our results may seem surprising in light of previous descriptions of Korean place assimilation (Kim-Renaud 1991, Ahn 1998). The results are less surprising when considered in the context of several recent cross-linguistic studies of place assimilation. Context-sensitivity - different implementation depending on specific phonetic contexts - has been observed for assimilation processes in other languages (Farnetani \& Busà 1994, Honorof 1999, Recasens \& Pallarès 2001, Kühnert \& Hoole 2004). Further, both categorical and gradient modes of implementation of assimilation have been found for English place assimilation, which has traditionally been described as a gradient phenomenon (Hardcastle \& Roach 1979, Barry 1991, Nolan 1992, Byrd 1996): for example, for the same lexical item, some speakers in the previously mentioned study by 
Ellis \& Hardcastle (2002) assimilated exclusively categorically, others did gradiently and still others did not assimilate at all. Given these findings in different languages, a larger-scale study of Korean place assimilation may uncover the role of additional factors in the process, as well as individual differences in its implementation at a microscopic level (see recent work by Son 2008).

Assuming, however, that the current results are representative of our speakers' grammatical knowledge of place assimilation, to what extent are the results consistent with Jun's $(1995,2004)$ account of Korean place assimilation? Overall, the account, summarised in (6) and Table I, appears to be too general to capture the variable implementation of the process by our speakers. In particular, it underpredicts the sensitivity of the process to contexts and word boundaries, differences between target places, and the degree of cross-speaker variability. At the same time, the account overpredicts the gradient realisation of the process. The account also posits a direct linear correlation between speech rate on the one hand and percentage of reduced tokens and degree of reduction on the other. Our results, however, suggest that this relation is, at best, a tendency (cf. Zsiga 1994, Byrd \& Tan 1996 on English place assimilation, Ellis \& Hardcastle 2002).

In terms of variability, making the account more compatible with our results would require introducing additional constraints referring to the place of following consonants and word boundaries, adjusting ranking probabilities as well as the probabilities of various degrees of reduction. Capturing individual differences in place assimilation would mean allowing for some variation across individual grammars - differences in certain aspects of constraint rankings (the relative probabilities of rankings and degrees of reduction).

Let us take our speaker K3 as an example. This subject's grammar does not allow for assimilation of labials and dorsals before coronals. Labials before dorsals are never assimilated across words, but are frequently assimilated within words. While the first effect is readily captured by Jun's constraint ranking, the second effect seems to require an extra constraint (e.g. Pres(pl[lab\#]), in addition to $\operatorname{Pres}(\mathrm{pl}[\mathrm{lab}]))$. Similar context-specific constraints are needed to capture boundary effects in coronal reduction: the speaker rarely assimilates coronals before dorsals within words, but does so frequently across words. Different patterns in the assimilation of coronals before labials and dorsals in turn require PRES(pl[cor]) constraints referring to place of articulation of the following consonant (i.e. Pres(pl[cor, _\#dors]), Pres(pl[cor, _ dors]), Pres(pl[cor, _\#lab]), $\operatorname{PREs}(\mathrm{pl}[\mathrm{cor}, \ldots$ lab])). To illustrate these modifications, (9) gives the ranking of constraints for an average slow-rate production by subject $\mathrm{K} 3$. This production involves assimilation of $/ \mathrm{t} /$ to $/ \mathrm{p} /$ in all contexts and to $/ \mathrm{k} /$ across words only (see Fig. 1a; cf. (6)). Note that the ranking capturing an average fast-rate production by the same speaker would differ only in the demotion of $\operatorname{PrEs}(\mathrm{pl}[\mathrm{lab}])$, resulting in labial assimilation within words. 
(9) Register: slow (based on reduction rate average for K3)

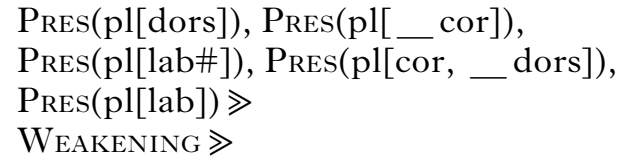

In addition, rankings of pairs of variably ranked constraints would have to be assigned non-identical probabilities (see Hayes \& Londe 2006 for such a proposal). Given the (admittedly weak) effect of speech rate, such probabilities can be adjusted for different speech registers. In sum, an O'T grammar capable of generating the range of variability found in K3's (and other subjects') productions has to include highly detailed, context-specific probabilistic constraints, possibly tailored to slow/careful and fast/informal registers, although the interaction of reduction and register is not yet fully understood.

While capturing the observed range of variability is in principle possible given the tools provided by stochastic OT, the questions of categorical/ gradient implementation and of its relation to speaking rate and style present a greater challenge. All three speakers in the current experiment showed a clear (albeit not absolute) preference for the categorical implementation of assimilation, which is not what Jun's rankings of gradient constraints predicted. To illustrate this mismatch, the original rankings in Table I are repeated in Table II, complemented with percentages of reduced tokens with various degrees of gestural reduction - those expected and actually observed for speaker K3. It is clear that the observed distribution is bipolar, showing either no reduction at all (ranking A; 29\% of all produced tokens) or complete reduction (ranking $\mathrm{K} ; 67 \%$ ). Gradient (partial) reduction accounts for only $4 \%$ of the speaker's production (3 tokens), compared to an expected $80 \%$ (assuming a random distribution of reduction patterns, a continuum from no reduction to full reduction). Further, some of the unreduced tokens were produced in fast speech, while some of the fully reduced tokens were produced in slow speech.

Overall, this shows that the relation between the presence and absence of assimilation, as well as that between categorical and gradient implementation, is rather indirect, mediated by other, not yet identified factors (cf. Zsiga 1994, Byrd \& Tan 1996, Ellis \& Hardcastle 2002). Most importantly, the results show that Korean place assimilation is a nearcategorical process, and this important property seems to be missed by an analysis that crucially relies on rankings of gradient OT constraints. In fact, this aspect of Korean place assimilation could have been captured better, and in a more economical fashion, by a traditional phonological account. Such an account would treat place assimilation as resulting from feature spreading in phonology (as in e.g. Ahn 1998; see (3)), with subsequent mapping of surface feature representations onto articulatory 


\begin{tabular}{|c|c|c|c|c|c|}
\hline \multirow[t]{2}{*}{ register } & \multicolumn{2}{|c|}{ slow/formal } & $\Leftrightarrow$ & \multicolumn{2}{|c|}{ fast/informal } \\
\hline & A & B & $\ldots$ & $\mathrm{J}$ & $\mathrm{K}$ \\
\hline \multirow[t]{14}{*}{ ranking } & $\mathrm{P}_{10}$ & $\mathrm{P}_{10}$ & \multirow{14}{*}{$\begin{array}{l}\cdots \\
\ldots \\
\ldots \\
\ldots \\
\ldots \\
\ldots \\
\ldots \\
\ldots \\
\ldots \\
\ldots \\
\ldots \\
\ldots \\
\ldots \\
\ldots\end{array}$} & $\mathrm{W}_{1 \mathrm{x}}$ & $\mathrm{W}_{1 \mathrm{x}}$ \\
\hline & $\mathrm{P}_{20}$ & $\mathrm{P}_{20}$ & & $\mathrm{~W}_{0 \cdot 9 \mathrm{x}}$ & $\mathrm{W}_{0 \cdot 9 \mathrm{x}}$ \\
\hline & $\ldots$ & $\ldots$ & & $W_{0 \cdot 8 x}$ & $\mathrm{~W}_{0 \cdot 8 \mathrm{x}}$ \\
\hline & $\mathrm{P}_{70}$ & $\mathrm{P}_{70}$ & & $\mathrm{~W}_{0 \cdot 7 \mathrm{x}}$ & $\mathrm{W}_{0 \cdot 7 \mathrm{x}}$ \\
\hline & $\mathrm{P}_{80}$ & $\mathrm{P}_{80}$ & & & 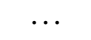 \\
\hline & $\mathrm{P}_{90}$ & $\mathrm{P}_{90}$ & & $\mathrm{~W}_{0 \cdot 2 \mathrm{x}}$ & $\mathrm{W}_{0 \cdot 2 \mathrm{x}}$ \\
\hline & $\mathrm{P}_{100}$ & $\mathrm{~W}_{1 \mathrm{x}}$ & & $\mathrm{P}_{10}$ & $\mathrm{~W}_{0 \cdot 1 \mathrm{x}}$ \\
\hline & $\mathrm{W}_{1 \mathrm{x}}$ & $\mathrm{P}_{100}$ & & $\mathrm{~W}_{0 \cdot 1 \mathrm{x}}$ & $\mathrm{P}_{10}$ \\
\hline & \multirow{6}{*}{$\begin{array}{c}\mathrm{W}_{0 \cdot 9 \mathrm{x}} \\
\mathrm{W}_{0 \cdot 8 \mathrm{x}} \\
\mathrm{W}_{0 \cdot 7 \mathrm{x}} \\
\ldots \\
\mathrm{W}_{0 \cdot 2 \mathrm{x}} \\
\mathrm{W}_{0 \cdot 1 \mathrm{x}}\end{array}$} & $\mathrm{W}_{0 \cdot 9 \mathrm{x}}$ & & $\mathrm{P}_{20}$ & $\mathrm{P}_{20}$ \\
\hline & & $\mathrm{W}_{0 \cdot 8 \mathrm{x}}$ & & $\ldots$ & $\ldots$ \\
\hline & & $\mathrm{W}_{0 \cdot 7 \mathrm{x}}$ & & $\mathrm{P}_{70}$ & $\mathrm{P}_{70}$ \\
\hline & & $\cdots$ & & $\mathrm{P}_{80}$ & $\mathrm{P}_{80}$ \\
\hline & & $\mathrm{W}_{0 \cdot 2 \mathrm{x}}$ & & $\mathrm{P}_{90}$ & $\mathrm{P}_{90}$ \\
\hline & & $\mathrm{W}_{0 \cdot 1 \mathrm{x}}$ & & $\mathrm{P}_{100}$ & $\mathrm{P}_{100}$ \\
\hline reduction degree & 0 & 10 & .. & 90 & 100 \\
\hline expected occurrence & $10 \%$ & $10 \%$ & $60 \%$ & $10 \%$ & $10 \%$ \\
\hline actual occurrence & $29 \%$ & $0 \%$ & $3 \%$ & $1 \%$ & $67 \%$ \\
\hline K3 & (21) & $(0)$ & $(2)$ & (1) & $(48)$ \\
\hline
\end{tabular}

Table II

Patterns of reduction expected on the basis of gradient constraint rankings and those observed in the experiment.

gestures (Zsiga 1997). Yet, the traditional account would face problems in predicting occasional gradience in the output - partial realisations of $\mathrm{C} 1$ gestures and the lack of consistent gestural extension of $\mathrm{C} 2$, as well as in capturing the variable application of the process.

Another possible account of Korean place assimilation would involve an extension of Kiparsky's (2007) analysis of English / $\mathrm{t} /$-deletion (similar to Hayes 1992), which assumes that categorical deletion and gradient reduction are inherently different processes. In this view, the lexicon contains multiple variants of a given lexical item, for instance a categorically reduced and a categorically unreduced variant of coda $/ t /$. Since lexical representations are based on unary or binary phonological feature values, the variants are a matter of all-or-none; gradience as a continuum of movement amplitudes is not part of the phonological representation. Each lexical item is associated with a frequency-based probability function and thus a likelihood of being selected. This accounts for the fact that very frequent words, such as function words, are more likely to undergo assimilation than infrequent words. Selection of different lexical variants 


\section{Alexei Kochetov and Marianne Pouplier}

will lead to categorically different outcomes - presence or absence of assimilation (categorically reduced/unreduced). Gradient reduction, however, is in Kiparsky's view purely phonetic in character, and presupposes the selection of the unreduced phonological variant. A phonologically fully present $/ t /$ can be implemented phonetically with a range of movement amplitudes (although the details of such implementation remain unclear).

Kiparsky's (2007) account predicts that subjects from the same speaker community (i.e. experiencing given lexical items roughly with the same frequency) should behave alike with respect to the selection probability of the phonological reduced/unreduced variants. Ellis \& Hardcastle's (2002) data for English, and our data for Korean, however, show that this is not the case. Speakers differ greatly in whether, in the same lexical item, they reduced categorically, gradiently or not at all. Speakers will necessarily experience different lexical items with different frequencies, and it is difficult to gauge how large these individual differences would have to be to lead to the intersubject variability we and other studies have observed. This concern limits the predictive power of an approach that strictly maintains a phonological/categorical $v s$. phonetic/gradient dichotomy. If differences in assimilatory behaviour were taken to be an index of the input frequencies for particular lexical items for any given speaker, the argument would become circular.

Kiparsky's approach is different from the traditional phonological analysis of assimilation discussed earlier, in that it encodes optionality into phonological representations or the lexicon. However, it takes essentially the same position on the relation between phonology and phonetics, strictly maintaining the phonological/categorical vs. phonetic/gradient dichotomy. One problem with this and other phonetics-after-phonology approaches is that (unlike Jun's and related gradient constraint approaches, e.g. Boersma 1998, Kirchner 1998) they fail to capture the relation between categorical assimilation and gradient reduction, missing an important generalisation that the two processes are in some sense 'the same'. That is, both categorical assimilation and gradient gestural reduction and extension are apparently governed by the same phonological factors (e.g. context, word boundary, etc.), exhibit similar regularities and, therefore, have to be part of speakers' internalised phonological knowledge (see e.g. Anttila 2003, 2007 on variability and gradience in other phonological processes).

The current data, as well as much of the experimental data on assimilation reviewed earlier, escape classification as either phonological or phonetic. Clearly, attempts to distinguish phonology from phonetics by clearly assigning every phenomenon to either one or the other are in many ways problematic. Speakers' grammars appear to be much more flexible and non-deterministic than afforded by a dichotomous phonology/ phonetics view. A more empirically adequate model of the phonologyphonetics interface should be able to represent speakers' knowledge of phonological processes of various dimensions and different degrees of 


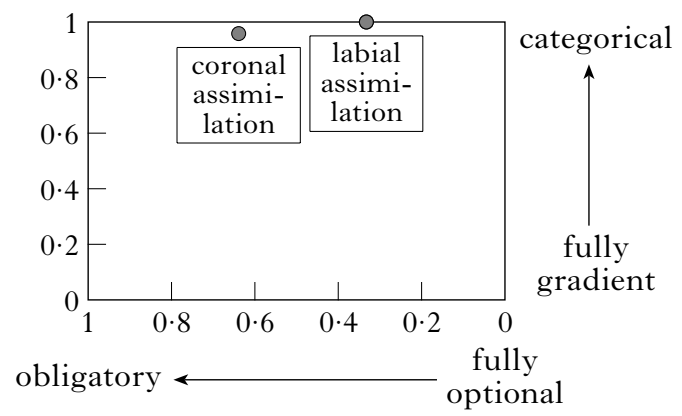

Figure 6

A schematic representation of coronal and labial assimilation as produced by speaker K3 (averaged over all conditions) in the optional/obligatory-gradient/categorical space.

abstractness, possibly as a continuum from optional to obligatory and from gradient to categorical (see Scobbie 2007 for a related proposal). A simplified schematic representation of these continua, representing speaker K3's (presumed) knowledge of coronal and labial assimilation, is shown in Fig. 6. On the optional/obligatory dimension, both processes are optional (variable), yet differ in the relative frequency of their application. On the gradient/categorical dimension, labial assimilation is fully categorical and phonological, while coronal assimilation in near-categorical and partly phonological/partly phonetic. Both optionality and gradience are further subject to various factors, such as phonological context, prosodic boundary and possibly word frequency.

The view of the phonology-phonetics interface as a continuum between optional/gradient and obligatory/categorical properties captures the relatedness of 'higher-level' phonological and 'lower-level' phonetic processes. The 'truly phonological' (obligatory and categorical) and 'truly phonetic' (optional and gradient) processes can be seen as opposite poles of what essentially are the same phenomena. Predictably, many processes (like Korean place assimilation) would fall somewhere in between, having both phonological and phonetic properties. This view is also useful in understanding the evolution of phonological processes. Thus place assimilation may originate as a fully optional and gradient phonetic effect, triggered by articulatory pressures and perceptual biases (e.g. Ohala 1990, Jun 1995, Kochetov et al. 2007). The process, internalised by speakers and subject to incremental grammatical/lexical generalisations, will inevitably drift towards the obligatory/categorical ends of the continua, and will eventually acquire full phonological status. Since speakers' linguistic generalisations are based on their individual experiences (Bybee 2001, Pierrehumbert 2001), some variation across speakers of the same dialect or language is fully expected. So is the variation in realisation of seemingly similar phonological processes in 
different languages (e.g. place assimilation in Korean, English and Spanish; see §1).

In sum, the present findings (and findings from other experimental studies of assimilation and deletion) are fully compatible neither with stochastic/phonetically based OT accounts nor with traditional phonology-after-phonetics accounts. What seems to be the major problem is the model of the interface between phonology and phonetics, which is either too rigid and deterministic (as in the case of traditional phonological accounts) or absent altogether (as in the case of phonetically driven accounts). An alternative view of the interface as an overlap rather than dichotomy (Scobbie 2007) provides a new and promising direction for research on variability and gradience in phonology.

\section{Conclusion}

Our articulatory investigation of Korean place assimilation has revealed a complex interaction between speaker idiosyncrasies and grammatical and phonetic factors. The frequency and implementation of place assimilation could be shown to be sensitive to the sequence of consonants involved, the presence of a word boundary and speaking rate, yet each of these factors contributes to a different degree to each individual's productions. Previous treatments of Korean place assimilation, such as the registerreferring OT account proposed by Jun, correctly predict differences in production according to different speaking rate/style conditions, but do not incorporate all the factors that seem to affect the assimilatory patterns observed. In conclusion, results of experimental investigations of variable and categorical/gradient phenomena pose new challenges to various phonological approaches, and seem to require us to reconsider traditional assumptions about what is phonological and what is phonetic.

\section{Appendix : Experimental procedure and measurements}

EMMA transducers were placed on the tongue tip (about $1 \mathrm{~cm}$ back from the actual tip), tongue body (two sensors), tongue dorsum, upper lip, lower lip and jaw. To correct for head movement, additional sensors were placed on the maxilla and nose ridge. Typical transducer placement is illustrated in Fig. 7. Articulatory data were sampled at $500 \mathrm{~Hz}$. Acoustic data was sampled at $48 \mathrm{kHz}$ for one subject and $20 \mathrm{kHz}$ for all other subjects.

For the tongue-tip and tongue-dorsum gestures for $/ \mathrm{t} /$ and $/ \mathrm{k} /$ respectively, constriction degree was calculated for the tongue-dorsum transducer coil. Tongue-tip/dorsum constriction degree (henceforth TTCD/TDCD) was calculated as the Euclidean distance of each sample of the relevant transducer coil to all sample points on the palate (the palate contour for each subject was resampled to fifty points). The minimal distance was taken as the constriction degree for that sample. A constriction degree value approximating zero thus indicates tongue-palate contact, as expected for a stop closure. For $/ \mathrm{p} /$ measurements, the time series for Lip Aperture (LA) was computed as the Euclidean distance between the upper-lip and lower-lip transducer coil. 


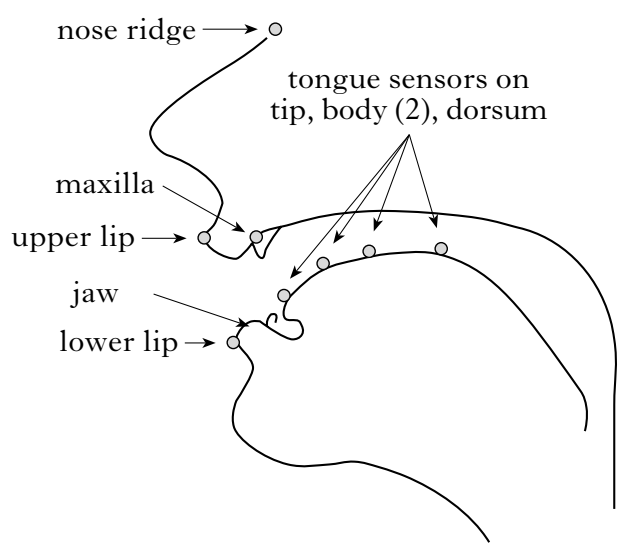

Figure 7

Schematic illustration of typical transducer placement.

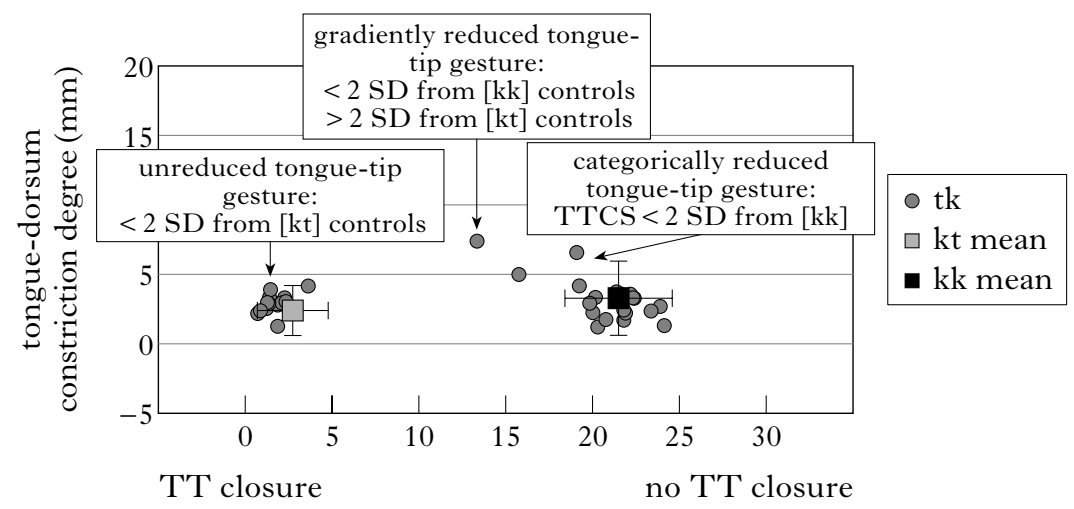

tongue-tip constriction degree $(\mathrm{mm})$

Figure 8

Illustration of classification method for / tk/ tokens for speaker K3.

Tongue-tip constriction degree during individual $/ \mathrm{tk} /$ tokens is evaluated against the distribution (mean $2 \mathrm{SD}$ ) of the $[\mathrm{kt}]$ and $[\mathrm{kk}]$ controls. The means for the control conditions are given with $2 \mathrm{SD}$ error bars.

Measurements were made at the minimum tongue-tip constriction degree during the sequences $/ \mathrm{tp} /$ and $/ \mathrm{tk} /$ : if no TTCD minimum was present (as is the case for a categorically reduced coronal and also for the non-coronal controls), TTCD was measured at the time point of the LA or TDCD minimum corresponding to the $/ \mathrm{p} /$ and $/ \mathrm{k} /$ gestures. To determine whether the coronal gesture was reduced (either partially or fully), target values were compared to the distribution of TTCD values found in the controls. $/ \mathrm{pt} /$ and $/ \mathrm{pp} /$ served as controls for $/ \mathrm{tp} / ; / \mathrm{kt} /$ and $/ \mathrm{kk} /$ served as controls for $/ \mathrm{tk} /$. A token was 


\section{Alexei Kochetov and Marianne Pouplier}

classified as 'unreduced' if its TTCD value was within two standard deviations of the mean TTCD value measured in the coronal controls.

A token was classified as 'fully reduced' if its TTCD value was within two standard deviations of the mean TTCD value obtained from the non-coronal control tokens (cf. (7c)). For those controls, TTCD was measured at the time point of the LA minimum in $/ \mathrm{pp} /$ (and compared to TTCD in $/ \mathrm{tp} /$ ) or at the time point of the TD minimum in $/ \mathrm{kk} /$ (these values served as comparison for TTCD during / tk/). If a token fell outside both control distributions, it was classified as 'partially reduced'. Figure 8 illustrates this metric on the basis of a subset of the data from K3.

It is worth pointing out that $/ t /$ in the control conditions is in onset position, and thus phonetically fortis (due to post-obstruent tensification; see $\S 3.1$ ); $/ \mathrm{t} /$ in the experimental condition, however, is in coda position, and thus phonetically lenis. There is evidence that the fortis and lenis stops in Korean differ not only in laryngeal setting, but also in linguopalatal contact (Kim et al. 2005). Similar observations have been made for voiced and voiceless coronal stops in a variety of languages (see Hamann \& Fuchs 2008 for a recent overview). Although tongue shape as a whole and the constriction location may differ inherently for our control and experimental conditions, our measure of constriction degree is less sensitive to such differences, since it is based on the Euclidean distance of the transducer to the nearest sample point on the palate, independently of where that sample point is on the palate. To further verify the validity of our classification criteria, we examined TTCD values of two utterances containing [tt'] (/mactambe/ 'smoking together' and /mas tajanhake/ 'various tastes') as well as intervocalic lenis [t] in the utterances/atam/ 'Adam (NOM)' and /mia takitfimja/ 'Mia is rushing' (collected during the same session). These values were comparable to the stops in the control conditions and gave us exactly the same results with respect to the classification of experimental tokens. In addition, measurements were made of the LA minimum for $/ \mathrm{pt} /$ and the TDCD minimum for $/ \mathrm{kt} /$ and $/ \mathrm{kp} /$, and compared to the respective gestures in $/ \mathrm{pp} \mathrm{tp} /$ and $/ \mathrm{kk} \mathrm{pk} /$, using the same criteria as described above.

To compare the duration of the $\mathrm{C} 2$ gestures in $/ \mathrm{tp} /$ and $/ \mathrm{tk} /$ to the duration of the same gestures in $/ \mathrm{pp} /$ and $/ \mathrm{kk} /$, we algorithmically identified the gestural landmarks 'target achievement' and 'release onset', based on onsets and offsets of motion in LA or TDCD velocity signals. Constriction duration was taken to be the distance between the target achievement and release onset of a gesture, in the literature also often referred to as 'plateau duration' (see Son et al. 2007).

\section{REFERENCES}

Ahn, Sang-Cheol (1998). An introduction to Korean phonology. Seoul: Hanshin.

Anttila, Arto (2003). Finnish assibilation. NELS 33. 13-24.

Anttila, Arto (2007). Variation and optionality. In Paul de Lacy (ed.) The Cambridge handbook of phonology. Cambridge: Cambridge University Press. 519-536.

Barry, Martin C. (1991). Temporal modelling of gestures in articulatory assimilation. In Proceedings of the 12th International Congress of Phonetic Sciences. Vol. 4. Aix-enProvence: Université de Provence. 14-17.

Blevins, Juliette (2004). Evolutionary Phonology: the emergence of sound patterns. Cambridge: Cambridge University Press. 
Blevins, Juliette (2007). Interpreting misperception: beauty is in the ear of the beholder. In Maria-Josep Solé, Patrice Streeter Beddor \& Manjari Ohala (eds.) Experimental approaches to phonology. Oxford: Oxford University Press. 144-154.

Boersma, Paul (1998). Functional phonology: formalizing the interactions between articulatory and perceptual drives. $\mathrm{PhD}$ dissertation, University of Amsterdam.

Boersma, Paul \& Bruce Hayes (2001). Empirical tests of the Gradual Learning Algorithm. LI 32. 45-86.

Browman, Catherine P. \& Louis Goldstein (1989). Articulatory gestures as phonological units. Phonology 6. 201-251.

Browman, Catherine P. \& Louis Goldstein (1992). Articulatory phonology: an overview. Phonetica 49. 155-180.

Browman, Catherine P. \& Louis Goldstein (1995). Dynamics and articulatory phonology. In Robert F. Port \& Timothy van Gelder (eds.) Mind as motion: explorations in the dynamics of cognition. Cambridge, Mass.: MIT Press. 175-194.

Bybee, Joan (2001). Phonology and language use. Cambridge: Cambridge University Press.

Byrd, Dani (1996). Influences on articulatory timing in consonant sequences. $\mathscr{F P h} 24$. 209-244.

Byrd, Dani \& Cheng Cheng Tan (1996). Saying consonant clusters quickly. $\mathscr{F P h} 24$. 263-282.

Chen, Larissa H. (2003). Evidence for the role of gestural overlap in consonant place assimilation. In Solé et al. (2003). 2821-2824.

Chitoran, Ioana \& Louis Goldstein (2006). Testing the phonological status of perceptual recoverability: articulatory evidence from Georgian. Poster presented at the 10th Conference on Laboratory Phonology, Paris.

Chitoran, Ioana, Louis Goldstein \& Dani Byrd (2002). Gestural overlap and recoverability: articulatory evidence from Georgian. In Carlos Gussenhoven \& Natasha Warner (eds.) Laboratory Phonology 7. Berlin \& New York: Mouton de Gruyter. 419-447.

Cho, Young-mee Yu (1990). Parameters of consonantal assimilation. PhD dissertation, Stanford University.

Chomsky, Noam \& Morris Halle (1968). The sound pattern of English. New York: Harper \& Row.

Coetzee, Andries W. (2004). What it means to be a loser: non-optimal candidates in Optimality Theory. PhD dissertation, University of Massachusetts, Amherst.

de Lacy, Paul (2002). The formal expression of markedness. PhD dissertation, University of Massachusetts, Amherst.

Docherty, Gerald J. \& D. Robert Ladd (eds.) (1992). Papers in laboratory phonology $I I$ : gesture, segment, prosody. Cambridge: Cambridge University Press.

Ellis, Lucy \& William J. Hardcastle (2002). Categorical and gradient properties of assimilation in alveolar to velar sequences: evidence from EPG and EMA data. $\mathscr{F P} h$ 30. 373-396.

Farnetani, Edda \& M. Grazia Busà (1994). Italian clusters in continuous speech. Proceedings of the 3rd International Conference on Spoken Language Processing (ICSLP 94). Yokohama: Acoustical Society of Japan. 359-361.

Gafos, Adamantios I. (2006). Dynamics in grammar: comment on Ladd and Ernestus \& Baayen. In Louis Goldstein, D. H. Whalen \& Catherine T. Best (eds.) Papers in laboratory phonology 8. Berlin \& New York: Mouton de Gruyter. 51-79.

Giles, Stephen B. \& Kenneth L. Moll (1975). Cinefluorographic study of selected allophones of English /1/. Phonetica 31. 206-227.

Gow, D. W., Jr. (2003). Feature parsing: feature cue mapping in spoken word recognition. Perception and Psychophysics 65. 575-590.

Guy, Gregory R. (1991). Contextual conditioning in variable lexical phonology. Language Variation and Change 3. 223-239. 


\section{Alexei Kochetov and Marianne Pouplier}

Hamann, Silke \& Susanne Fuchs (2008). Retroflexion of voiced stops: data from Dhao, Thulung, Afar and German. Ms, under review.

Hardcastle, W. J. \& P. J. Roach (1979). An instrumental investigation of coarticulation in stop consonant sequences. In Harry Hollien \& Patricia Hollien (eds.) Current issues in the phonetic sciences. Amsterdam: Benjamins. 531-540.

Hayes, Bruce (1992). Comments on chapter 10. In Docherty \& Ladd (1992). 280-286.

Hayes, Bruce \& Zsuzsa Cziráky Londe (2006). Stochastic phonological knowledge: the case of Hungarian vowel harmony. Phonology 23. 59-104.

Honorof, Douglas (1999). Articulatory gestures and Spanish nasal assimilation. PhD dissertation, Yale University.

Hume, Elizabeth (2003). Language specific markedness: the case of place of articulation. Studies in Phonetics, Phonology and Morphology 9. 295-310.

Jun, Jongho (1995). Perceptual and articulatory factors in place assimilation: an Optimality-theoretic approach. PhD dissertation, University of California, Los Angeles.

Jun, Jongho (1996). Place assimilation is not the result of gestural overlap: evidence from Korean and English. Phonology 13. 377-407.

Jun, Jongho (2004). Place assimilation. In Bruce Hayes, Robert Kirchner \& Donca Steriade (eds.) Phonetically based phonology. Cambridge: Cambridge University Press. 58-86.

Jun, Sun-Ah (1993). The phonetics and phonology of Korean prosody. PhD dissertation, Ohio State University.

Jun, Sun-Ah (1998). The Accentual Phrase in the Korean prosodic hierarchy. Phonology 15. 189-226.

Kim-Renaud, Young-Key (1991). Korean consonantal phonology. Seoul: Hanshin.

Kim, Hyunsoon, Kiyoshi Honda \& Shinji Maeda (2005). Stroboscopic-cine MRI study of the phasing between the tongue and the larynx in the Korean three-way phonation contrast. $\mathscr{F}$ h 33. 1-26.

Kiparsky, Paul (1985). Some consequences of Lexical Phonology. Phonology Yearbook 2. 85-138.

Kiparsky, Paul (2007). Variation as a window into phonological organization. Paper presented at the LSA Workshop on Variation in Phonology, Stanford.

Kirchner, Robert (1998). An effort-based approach to consonant lenition. PhD dissertation, University of California, Los Angeles.

Kochetov, Alexei, Marianne Pouplier \& Minjung Son (2007). Cross-language differences in overlap and assimilation patterns in Korean and Russian. Proceedings of the 16th International Congress of Phonetic Sciences, Saarbrücken. 1361-1364.

Kochetov, Alexei \& Connie K. So (2007). Place assimilation and phonetic grounding: a cross-linguistic perceptual study. Phonology 24. 397-432.

Kühnert, Barbara \& Philip Hoole (2004). Speaker-specific kinematic properties of alveolar reductions in English and German. Clinical Linguistics and Phonetics 18. $559-575$.

Kühnert, Barbara, Philip Hoole \& Christine Mooshammer (2006). Gestural overlap and C-center in selected French consonant clusters. Proceedings of the 7th International Seminar on Speech Production, Ubatuba, Brazil. 327-334.

Lindblom, Björn (1990). Explaining phonetic variation: a sketch of the H\&H theory. In W. J. Hardcastle \& Alain Marchal (eds.) Speech production and speech modelling. Dordrecht: Kluwer. 403-439.

Marslen-Wilson, William \& Paul Warren (1994). Levels of perceptual representation and process in lexical access: words, phonemes, and features. Psychological Review 101. 653-675.

Nolan, Francis (1992). The descriptive role of segments: evidence from assimilation. In Docherty \& Ladd (1992). 261-280. 
Nolan, Francis, Tara Holst \& Barbara Kühnert (1996). Modelling [s] to [S] accommodation in English. $\mathscr{F} P h$ 24. 113-137.

Ohala, John J. (1990). The phonetics and phonology of aspects of assimilation. In John Kingston \& Mary E. Beckman (eds.) Papers in laboratory phonology I : between the grammar and physics of speech. Cambridge: Cambridge University Press. 258-275.

Perkell, Joseph S., Marc H. Cohen, Mario A. Svirsky, Melanie L. Matthies, Iñaki Garabieta \& Michael T. T. Jackson (1992). Electromagnetic midsagittal articulometer systems for transducing speech articulatory movements. $\mathcal{F} A S A \mathbf{9 2}$. 3078-3096.

Pierrehumbert, Janet B. (2001). Exemplar dynamics: word frequency, lenition and contrast. In Joan Bybee \& Paul Hopper (eds.) Frequency and the emergence of linguistic structure. Amsterdam \& Philadelphia: Benjamins. 137-157.

Pouplier, Marianne (2003). The dynamics of error. In Sole et al. (2003). 2245-2248.

Recasens, Daniel \& Maria Dolors Pallarès (2001). Coarticulation, assimilation and blending in Catalan consonant clusters. FPh 29. 273-301.

Rice, Keren (1999). Featural markedness in phonology: variation. Glot International 4:7. 3-6, 4:8. 3-7.

Scobbie, James M. (2007). Interface and overlap in phonetics and phonology. In Gillian Ramchand \& Charles Reiss (eds.) The Oxford handbook of linguistic interfaces. Oxford: Oxford University Press. 17-52.

Scobbie, James M., Marianne Pouplier \& Alan Wrench (2007). Conditioning factors in external sandhi: an EPG study of English /1/ vocalisation. Proceedings of the 16th International Congress of Phonetic Sciences, Saarbrücken. 441-444.

Solé, M. J., D. Recasens \& J. Romero (eds.) (2003). Proceedings of the 15th International Congress of Phonetic Sciences. Barcelona: Causal Productions.

Son, Minjung (2008). The nature of Korean place assimilation: gestural overlap and gestural reduction. PhD dissertation, Yale University.

Son, Minjung, Alexei Kochetov \& Marianne Pouplier (2007). The role of gestural overlap in perceptual place assimilation in Korean. In Jennifer Cole \& José Ignacio Hualde (eds.) Laboratory phonology 9. Berlin \& New York: Mouton de Gruyter. 507-534.

Sproat, Richard \& Osamu Fujimura (1993). Allophonic variation in English /1/ and its implications for phonetic implementation. $\mathscr{P}$ h 21. 291-311.

Tiede, Mark, Srefanie Shattuck-Hufnagel, Beth Johnson, Satrajit Ghosh, Melanie Matthies, Madjid Zandipour \& Joseph Perkell (2007). Gestural phasing in /kt/ sequences contrasting within and cross word contexts. Proceedings of the 16th International Congress of Phonetic Sciences, Saarbrücken. 521-524.

Wright, Susan \& Paul Kerswill (1989). Electropalatography in the analysis of connected speech processes. Clinical Linguistics and Phonetics 3. 49-57.

Zsiga, Elizabeth C. (1994). Acoustic evidence for gestural overlap in consonant sequences. $\mathscr{F P h} 22.121-140$.

Zsiga, Elizabeth C. (1997). Features, gestures, and Igbo vowels: an approach to the phonology-phonetics interface. $\operatorname{Lg}$ 73. 227-274. 